OPEN ACCESS

Edited by:

Dominique Sanglard, University of Lausanne, Switzerland

Reviewed by: Miguel Cacho Teixeira, University of Lisbon, Portugal Richard Cannon, University of Otago, New Zealand

*Correspondence: Gábor Nagy nagygab86@gmail.com

Specialty section: This article was submitted to Fungal Pathogenesis,

a section of the journal Frontiers in Cellular and Infection Microbiology

Received: 29 January 2021 Accepted: 19 March 2021 Published: 14 April 2021

Citation:

Nagy G, Kiss S, Varghese R, Bauer K, Szebenyi C, Kocsubé S, Homa M

Bodai L, Zsindely N, Nagy G, Vágvölgyi $C$ and Papp T (2021) Characterization of Three Pleiotropic Drug Resistance Transporter Genes and Their Participation in the Azole Resistance of Mucor circinelloides. Front. Cell. Infect. Microbiol. 11:660347. doi: 10.3389/fcimb.2021.660347

\section{Characterization of Three Pleiotropic Drug Resistance Transporter Genes and Their Participation in the Azole Resistance of Mucor circinelloides}

\author{
Gábor Nagy ${ }^{1,2 *}$, Sándor Kiss ${ }^{1}$, Rakesh Varghese ${ }^{1}$, Kitti Bauer ${ }^{1}$, Csilla Szebenyi ${ }^{1,2}$, \\ Sándor Kocsubé ${ }^{1}$, Mónika Homa ${ }^{1,2}$, László Bodai ${ }^{3}$, Nóra Zsindely $^{1}$, Gábor Nagy ${ }^{3}$, \\ Csaba Vágvölgyi ${ }^{1}$ and Tamás Papp ${ }^{1,2}$ \\ ${ }^{1}$ Department of Microbiology, Faculty of Science and Informatics, University of Szeged, Szeged, Hungary, ${ }^{2}$ MTA-SZTE \\ "Lendület" Fungal Pathogenicity Mechanisms Research Group, Department of Microbiology, University of Szeged, Szeged, \\ Hungary, ${ }^{3}$ Department of Biochemistry and Molecular Biology, Faculty of Science and Informatics, University of Szeged, \\ Szeged, Hungary
}

Mucormycosis is a life-threatening opportunistic infection caused by certain members of the fungal order Mucorales. This infection is associated with high mortality rate, which can reach nearly $100 \%$ depending on the underlying condition of the patient. Treatment of mucormycosis is challenging because these fungi are intrinsically resistant to most of the routinely used antifungal agents, such as most of the azoles. One possible mechanism of azole resistance is the drug efflux catalyzed by members of the ATP binding cassette $(A B C)$ transporter superfamily. The pleiotropic drug resistance (PDR) transporter subfamily of $\mathrm{ABC}$ transporters is the most closely associated to drug resistance. The genome of Mucor circinelloides encodes eight putative PDR-type transporters. In this study, transcription of the eight $p d r$ genes has been analyzed after azole treatment. Only the pdr1 showed increased transcript level in response to all tested azoles. Deletion of this gene caused increased susceptibility to posaconazole, ravuconazole and isavuconazole and altered growth ability of the mutant. In the pdr1 deletion mutant, transcript level of $p d r 2$ and $p d r 6$ significantly increased. Deletion of $p d r 2$ and $p d r 6$ was also done to create single and double knock out mutants for the three genes. After deletion of pdr2 and pdr6, growth ability of the mutant strains decreased, while deletion of pdr2 resulted in increased sensitivity against posaconazole, ravuconazole and isavuconazole. Our result suggests that the regulation of the eight pdr genes is interconnected and pdr1 and pdr2 participates in the resistance of the fungus to posaconazole, ravuconazole and isavuconazole.

Keywords: Mucor, pleiotropic drug resistance, CRISPR-Cas9, azole, ABC transporter

\section{INTRODUCTION}

Mucorales species are ubiquitous saprophytes (Hoffmann et al., 2013), but several species are also known as opportunistic human pathogens, which can cause a life-threatening infection commonly called as mucormycosis. The most common mucormycosis-causing agent is Rhizopus delemar (also referred to as $R$. arrhizus var. delemar and $R$. oryzae) (Walther et al., 2019), which can cause 
mucormycosis worldwide, followed by Lichtheimia, Apophysomyces, Rhizomucor, Mucor and Cunninghamella species (Prakash and Chakrabarti, 2019). Besides the pathogenesis of $R$. delemar, those of Lichtheimia corymbifera and Mucor circinelloides, have also been studied (Riley et al., 2016; Skiada et al., 2018; Jeong et al., 2019). Clinical manifestations of mucormycosis include rhino-cerebral, pulmonary, cutaneous, and disseminated forms in immunocompromised patients (Skiada et al., 2018; Jeong et al., 2019). These infections are generally associated with rapid progression and high mortality rates (i.e. from 20 to $100 \%$ depending on the underlying condition, the clinical presentation, and the treatment), furthermore, their diagnosis and treatment are often difficult (Riley et al., 2016; Skiada et al., 2018). The immunocompromised state due to malignancy (Ibrahim et al., 2012; Riley et al., 2016; Skiada et al., 2018) or immunosuppressive treatments (Bakr et al., 2008; Ibrahim et al., 2012), diabetic ketoacidosis (Roden et al., 2005; Rammaert et al., 2012; Roilides et al., 2012), corticosteroid treatment (Prabhu and Patel, 2004), malnutrition (Sun and Singh, 2011), burn and trauma (Riley et al., 2016) are the main risk factors for the infection. For the treatment of mucormycosis, international guidelines recommend systemic antifungal therapy in combination with surgical intervention (Caramalho et al., 2017; Skiada et al., 2018). The first-choice antifungal agent against Mucorales fungi is amphotericin B. Besides, application of two triazoles, posaconazole and isavuconazole are approved for second-line or salvage therapy (Riley et al., 2016). However, the spectrum of applicable drugs is extremely narrow as these fungi are intrinsically resistant to most of the routinely used antifungal agents including most azoles (Almyroudis et al., 2007; Drogari-Apiranthitou et al., 2012; Riley et al., 2016).

The specific target of azoles is a cytochrome P450 enzyme, the lanosterol $14 \alpha$-demethylase enzyme (Cyp51 or Erg11), which catalyzes an intermediate step of the ergosterol biosynthesis, the conversion of lanosterol to 4,4-dimethyl-cholesta-8,14,24trienol. Ergosterol is the main sterol component of the fungal cell membrane. Blocking of its synthesis causes accumulation of toxic $14 \alpha$-methyl sterols, which alter the stability and permeability of the cell membrane (Odds et al., 2003). Development of antifungal resistance is a complex process and depends on either host- and microbial related factors (White et al., 1998). In the case of azoles, the resistance mechanisms most frequently include alterations in ergosterol biosynthetic enzymes and up-regulation of multidrug transporters (Cowen et al., 2015).

Expression of drug efflux pumps, which belong to the ATPbinding cassette (ABC) or the major facilitator superfamily (MFS) transporters, was found to a major factor contributing in the fungal resistance to azoles in several human pathogenic fungi (Prasad and Rawal, 2014; Holmes et al., 2016; Lopez-Ribot et al., 2017; Sharma and Chowdhary, 2017). In Candida albicans, two $\mathrm{ABC}$ transporters belonging to the pleiotropic drug resistance (PDR) protein class of $\mathrm{ABC}$ transporter superfamily, Candida drug resistance $1(\mathrm{Cdr} 1)$ and $\mathrm{Cdr} 2$ were found to have the primary role in the azole resistance (Rocha et al., 2017).
$C d r$ genes responsible for azole efflux have also been identified and characterized in other Candida species (Rocha et al., 2017). Overexpression of the Cryptococcus neoformans antifungal resistance 1 (AFR1) protein, which also belongs to the PDR family, led to resistance to fluconazole and an increased virulence in mouse models (Chang et al., 2018). In the case of Aspergillus fumigatus, the role of the $\mathrm{ABC}$ transporter $\mathrm{Cdr} 1 \mathrm{~B}$ in itraconazole, voriconazole and posaconazole resistance was proven (Fraczek et al., 2013; Hagiwara et al., 2017), but other ABC transporter genes were also found to be upregulated after azole treatment (Lopez-Ribot et al., 2017).

Little is known about the background of azole resistance in mucormycosis-causing fungi. It is assumed that specific amino acid substitutions in one of the Cyp51 enzymes can affect the sensitivity of these fungi to several azoles, such as fluconazole or voriconazole (Caramalho et al., 2017). However, the role of drug efflux pumps in azole resistance have not been examined in this fungal group. $M$. circinelloides belongs to the order Mucorales and it is a widely used model organism in genetic and molecular biological studies, among others on light sensing (Corrochano and Garre, 2010; Vellanki et al., 2018; Yu and Fischer, 2019; Navarro et al., 2020), molecular regulation and signal processes (Lee et al., 2015; Ruiz-Vázquez et al., 2015; Calo et al., 2017; Lax et al., 2020), morphogenesis (Lee et al., 2015; Moriwaki-Takano et al., 2020; Vellanki et al., 2020), carotenogenesis (Zhang et al., 2016; Alcalde et al., 2019) and pathogenicity (Li et al., 2011; López-Fernández et al., 2018; Patiño-Medina et al., 2019). In this study, transcription of the eight genes of $M$. circinelloides possibly encoding PDR-type ABC transporters was analyzed and three of them (named as $p d r 1, p d r 2$ and $p d r 6$ ) were knocked out by CRISPR-Cas9 mutagenesis. Using the knockout mutants, the effect of these transporters on the azole resistance was examined.

\section{MATERIALS AND METHODS}

\section{Strains, Media, and Growth Conditions}

Mucor circinelloides strain MS12 (leuA $A^{-}$and pyrG ${ }^{-}$) (Benito et al., 1992) was used in the study. For nucleic acid extraction from Mucor, $10^{6}$ sporangiospores were plated onto solid minimal medium (YNB; $10 \mathrm{~g}$ glucose, $0.5 \mathrm{~g}$ yeast nitrogen base without amino acids (Sigma-Aldrich), $1.5 \mathrm{~g}\left(\mathrm{NH}_{4}\right)_{2} \mathrm{SO}_{4}, 1.5 \mathrm{~g}$ sodium glutamate and $20 \mathrm{~g}$ agar per liter) supplemented with leucine and/or uracil $(0.5 \mathrm{mg} / \mathrm{ml})$ if required. In some cases, RNA extraction was performed after cultivation in $30 \mathrm{ml} \mathrm{RPMI-1640}$ without agar (Biosera); the inoculum size was $10^{4}$ sporangiospores $/ \mathrm{ml}$. Fungal cultures were grown for 4 days under continuous light at $25^{\circ} \mathrm{C}$.

To test the effect of azoles on the gene expression, after cultivating the fungus in $10 \mathrm{ml}$ liquid RPMI-1640 for $24 \mathrm{~h}$ at $25^{\circ} \mathrm{C}$, it was treated with the corresponding azoles and incubated for another $16 \mathrm{~h}$ before the RNA extraction. Ketoconazole (Alfa Aesar), itraconazole (Across Organics), fluconazole (Alfa Aesar), ravuconazole (Sigma Aldrich) and isavuconazole (Sigma Aldrich) were applied in a final concentration of $8 \mu \mathrm{g} / \mathrm{ml}$, 
while the final concentration of posaconazole (Sigma Aldrich) was $2 \mu \mathrm{g} / \mathrm{ml}$. Anaerobic growth was performed in a BBL GasPak Anaerobic System (Becton Dickinson) at $25^{\circ} \mathrm{C}$. For the antifungal susceptibility test, Candida krusei ATCC 6258 was used as a reference strain. After cultivating Mucor in liquid RPMI-1640 for $24 \mathrm{~h}$ at $25^{\circ} \mathrm{C}$, it was treated with the corresponding azole (i.e., ketoconazole, itraconazole, fluconazole, posaconazole, ravuconazole or isavuconazole), and incubated for another $16 \mathrm{~h}$ before RNA extraction.

To measure the colony diameters of the strains, $10^{4}$ sporangiospores were inoculated onto the center of solid YNB plates. The diameter of the colonies was measured daily after incubating the plates at $25^{\circ} \mathrm{C}$ using the MS12 strain as the growth control. In the experiment, we measured the colony diameter of two colonies using three biological and two technical replicates.

\section{Molecular Techniques}

General procedures for plasmid DNA preparation, cloning and transformation of $E$. coli $\mathrm{DH} 5 \alpha$ were performed by following standard methods (Sambrook et al., 1989). Plasmid DNA was isolated using the PureYield Plasmid Miniprep System (Promega).

Genomic DNA and RNA samples were purified from mycelia using the ZR Fungal/Bacterial DNA MiniPrepTM (Zymo Research) and the Quick-RNA MiniPrep kit (Zymo Research), respectively, according to the manufacturers' instructions. Genes were amplified by PCR using the Phusion Flash High-Fidelity PCR Master Mix (Thermo Scientific) and the primers presented in Supplementary Table 1. Primer and oligonucleotide sequences were designed using the $M$. circinelloides CBS277.49v2.0 genome database (DoE Joint Genome Institute; http://genome.jgi-psf.org/Mucci2/Mucci2.home.html) (Corrochano et al., 2016).

\section{Sequence Analysis}

Sequencing was commercially performed by LGC Genomics (Berlin, Germany). Amino acid sequences obtained from $M$. circinelloides CBS277.49v2.0 genome database and Cryptococcus neoformans Afr1 (UniProtKB: Q8X0Z3) were aligned using the ClustalW program (Higgins et al., 1996). BLAST searches were performed at the site of the National Center for Biotechnology Information (NCBI) (https://blast.ncbi.nlm.nih.gov/Blast.cgi.

Programs used to analyze the amino acid sequences of the putative PDR proteins were accessed throught the Swiss Expasy Server (http://www.expasy.ch) (Gasteiger et al., 2005). Domain search and prediction were performed using the Motif Scan (MyHits) program (Pagni et al., 2007).

Homologous sequences of Cryptococcus neoformans var. neoformans JEC21 AFR1 were searched on the JGI MycoCosm portal (https://mycocosm.jgi.doe.gov/mycocosm/home) (Grigoriev et al., 2014). Sequences with at least 50\% identity were retrieved and hits from non-public genomes were removed. The remaining sequences were clustered by using MMseqs $2 \mathrm{v}$. bbd564172bd55d9e6acd1170e59790c37157a21b (Steinegger and Söding, 2017). The sensitivity of the cascaded clustering was set to 7.5 applying the cluster reassign mode. Maximum Likelihood analysis was conducted with the cluster comprising of 853 sequences including the AFR1 protein and the 8 examined PDR proteins from $M$. circinelloides CBS 277.49 (for the sequences included see Supplementary Table 2). Sequences were aligned using MAFFT v. 7.453 (Katoh and Standley, 2013) with the EINS-i iterative refinement method. Poorly aligned regions were removed by using trimAl v. 1.2rev57 (Capella-Gutierrez et al., 2009) with the -automated 1 option. Phylogenetic reconstruction was carried out by using IQ-TREE v. 1.6.12 (Nguyen et al., 2015) with the LG4M+R6 model determined by the inbuilt model selection tool (Kalyaanamoorthy et al., 2017). Branch supports were calculated with 5000 ultrafast bootstrap (Hoang et al., 2018).

\section{Real-Time Quantitative Reverse Transcription PCR Analysis}

Reverse transcription was carried out with the Maxima $\mathrm{H}$ Minus First Strand cDNA Synthesis Kit (Thermo Scientific) using random hexamer and oligo (dT)18 primers, following the instructions of the manufacturer. The qRT-PCR experiments were performed in a CFX96 real-time PCR detection system (Bio-Rad) using the Maxima SYBR Green qPCR Master Mix (Thermo Scientific) and the primers presented in Supplementary Table 1. The relative quantification of the copy number and the gene expression was achieved with the $2^{-\Delta \Delta \mathrm{Ct}}$ method (Livak and Schmittgen, 2001) using the actin gene of M. circinelloides as a reference (Nagy et al., 2014). Experiments were performed in biological and technical triplicates.

\section{Design of the gRNAs and Construction of the Disruption Cassettes to Disrupt the pdr Genes by the CRISPR-Cas9 Method}

The protospacer sequences designed to target the DNA cleavage in pdr1 (CBS277.49v2.0 genome database Protein Id: 48059), pdr2 (CBS277.49v2.0 genome database Protein Id: 83305) and pdr6 (CBS277.49v2.0 genome database Protein Id: 146716) genes were the followings, $5^{\prime}$ - tttatgaacttgtgtatgaa - 3', 5'- tgctgatttc gagcgtatcac $-3^{\prime}$ and 5'- ctatattgctcaagtcatca $-3^{\prime}$, respectively. Using these sequences, the Alt-R CRISPR crRNA and AltRCRISPR-Cas9 tracrRNA molecules were designed and purchased from Integrated DNA Technologies (IDT). To form the crRNA:tracrRNA duplexes (i.e. the gRNAs), the NucleaseFree Duplex Buffer (IDT) was used according to the instructions of the manufacturer. Genome editing strategies followed the setup described earlier (Nagy et al., 2017). Homology direct repair (HDR) was applied for all gene disruptions following the strategy described previously (Nagy et al., 2017). Disruption cassettes functioning also as the template DNA for the HDR were constructed by PCR using the Phusion Flash High-Fidelity PCRMaster Mix (Thermo Scientific). At first, two fragments, upstream from start codon and downstream from stop codons of the targeted gene and the $M$. circinelloides pyrG gene (CBS277.49v2.0 genome database Protein Id: 36136) or $M$. circinelloides leuA gene (CBS277.49v2.0 genome database Protein Id: 33992) along with its own promoter and terminator sequences were amplified using gene specific primer pairs (see Supplementary Table 1). The amplified fragments were fused in a subsequent PCR using nested primers (see Supplementary

Table 1); the ratio of the fragments in the reaction was 1:1:1. 


\section{Construction of the pPdr1compl Plasmid Used to Complement the Deletion of the pdr1 Gene}

The leuA gene (CBS277.49v2.0 genome database ID: Mucci.e_gw1.2.132.1) using gene specific primers was amplified from the genomic DNA of the MS12 strain (Supplementary Table 1) and ligated into pJET1.2/blunt plasmid (Thermo Scientific) to create the plasmid pJet+leuA. The $p d r 1$ gene was amplified together with its own promoter and terminator regions using gene specific primers (Supplementary Table 1) and the resulting fragment was also ligated into pJet1.2/ blunt vector to create the plasmid pJet+pdr1. Then, $p d r 1$ together with its regulatory regions was cut from this plasmid by the enzyme NotI and ligated at the same restriction site of pJet+leuA to construct pPdr1compl plasmid (Supplementary Figure 1A). This plasmid was used to introduce to the MS12- $\Delta p d r 1$ to create MS12- $\Delta p d r 1+p P d r 1$ compl strains. The complemented $p d r 1$ gene was amplified by PCR using Mc48059P7 and Mc48059P8 primers (Supplementary Figure $1 \mathbf{B}$ and Supplementary Table 1).

\section{Transformation Experiments}

For the CRISPR-Cas9-mediated gene knock out and the complementation of the $\Delta p d r 1$ gene, the PEG-mediated protoplast transformation method was used according to van Heeswijck and Roncero (1984). Protoplasts were prepared as described earlier (Nagy et al., 1994). For the gene disruption by CRISPR-Cas9 method, $5 \mu \mathrm{g}$ template DNA (disruption cassette), $10 \mu \mathrm{M}$ gRNA and $10 \mu \mathrm{M}$ Cas9 nuclease were added to the protoplasts in one transformation reaction as described by Nagy et al. (2019). To complement the deletion of the pdr1, $5 \mu \mathrm{g}$ pPdr1compl plasmid DNA was added into one transformation reaction. In each case, transformants were selected on solid YNB medium by the complementation of the uracil and/or leucine auxotrophy of the MS12 strain. From each primary transformant, monosporangial colonies were formed under selective conditions. Deletion of genes was confirmed by sequencing in all cases while the absence of the transcripts of the deleted genes was proven by qRT-PCR.

\section{Measurement of Energy-Dependent Rhodamine 6G Efflux}

Measurement of R6G efflux was analyzed according to Gbelska et al. (2017). Sporangiospores of the strains $\left(10^{7}\right)$ were inoculated in $10 \mathrm{ml} \mathrm{YNB}$ and incubated in a fridge for $16 \mathrm{~h}$. The spores were then incubated for $4 \mathrm{~h}$ at $25^{\circ} \mathrm{C}$ under continuous shaking at 220 rpm. Germinating spores were collected by centrifuging the samples for $10 \mathrm{~min}$ at $4^{\circ} \mathrm{C}$ at $2000 \times g$. The pellets were washed two times with ice-cold PBS buffer and 2-deoxy-D-glucose and R6G were added to the cells in final concentrations of $2 \mathrm{mM}$ and $100 \mu \mathrm{M}$, respectively. Fungal cells were incubated for $2 \mathrm{~h}$ at $25^{\circ} \mathrm{C}$ in dark, washed two times with ice cold PBS and finally resuspended in PBS. Then, D-glucose were added to the samples, in a final concentration of $2 \mathrm{nM}$. After incubation for 10, 20 and $30 \mathrm{~min}, 400 \mu \mathrm{l}$ of the samples were centrifuged for
2 min at $8000 \times g$ and $100 \mu \mathrm{l}$ of the supernatants were transferred into a 96-wells black plate. The fluorescence signal was measured using a fluorimeter (FLUOstar OPTIMA, BMG Labtech) where the excitation filter was 520BP1 and the emission filter was 59010. Experiments were performed in biological and technical triplicates. To determine the R6G concentration, a standard curve was generated using the following concentrations: 0,100 , 250, 500 and $1000 \mathrm{nM}$.

\section{Susceptibility Tests}

Sensitivity of the fungal strains to different antifungal agents, and $\mathrm{H}_{2} \mathrm{O}_{2}$ was examined in a 96-well microtiter plate assay. The susceptibility test was performed according to the CLSI recommendation (Rex and Clinical, 2008) in three biological replicates. Ketoconazole (Alfa Aesar), itraconazole (Across Organics), fluconazole (Alfa Aesar), ravuconazole (Sigma Aldrich), posaconazole (Sigma Aldrich), isavuconazole (Sigma Aldrich), amphotericin B (Sigma Aldrich), hygromycin B (Sigma Aldrich), terbinafine (Sigma Aldrich), micafungin (Sigma Aldrich) and cyclohexymide (PanReac AppliChem) were dissolved in DMSO to prepare the stock. These stocks were then diluted with liquid RPMI-1640 medium. Final concentrations of ketoconazole, itraconazole, fluconazole, terbinafine and micafungin in the wells ranged from 0.125 to $64 \mu \mathrm{g} / \mathrm{ml}$ while those of ravuconazole and isavuconazole ranged from 0.125 to $16 \mu \mathrm{g} / \mathrm{ml}$. In the case of posaconazole and amphotericin $B$, the range was 0.125 to $8 \mu \mathrm{g} / \mathrm{ml}$. Cyclohexymide were diluted in RPMI-1640 to obtain a range of $250-0,78 \mu \mathrm{g} / \mathrm{ml}$. Hydrogen peroxide was diluted in liquid RPMI1640 to prepare a stock solution of $100 \mathrm{mM}$. Final concentrations of the hydrogen peroxide in the wells ranged from 0 to $10 \mathrm{mM}$. Inocula were prepared and diluted in liquid RPMI-1640. Plates were incubated for $48 \mathrm{~h}$ at $25^{\circ} \mathrm{C}$.

\section{Statistical Analysis}

All measurements were performed in at least two technical and three biological replicates. Significance was calculated with paired t-test or One-way Anova using the Graph Pad Prism 7 program. P values less than 0.05 were considered as statistically significant.

\section{RESULTS}

\section{Characteristic Features of PDR Proteins of Mucor circinelloides}

In the $M$. circinelloides genome database (DoE Joint Genome Institute; $M$. circinelloides CBS277.49v2.0; http://genome.jgi-psf. org/Mucci2/Mucci2.home.html), eight potential PDR proteins were found by amino acid similarity search using the amino acid sequence of Cryptococcus neoformans Afr1 (UniProtKB: Q8X0Z3) and Candida albicans Cdr1p (UniProtKB: P43071). The identity of amino acid sequences was between 36.8 and $39.6 \%$. Despite the low identity values, the characteristic motifs of the 8 putative Pdr proteins could be identified. Protein ID, 
location and amino acid length are shown in Table 1. In all eight putative PDR proteins, the amino acid motifs characteristic to the PDR family, such as the first and second Walker-A and B sequences, the first and second $\mathrm{ABC}$ signature motifs (Posteraro et al., 2003) and the conserved PDR specific NBD1 (T/SL/FLK/RT/V/II/L) and NBD2 (TLLN/DC/VL/R) motifs (Rawal et al., 2016) were identified (Supplementary Figure 2). PDR/CDR ABC motifs (Gauthier et al., 2003) were also identified in all eight putative PDR proteins using the motif scan (MyHits) program (Table 1).

Comparing the amino acid sequences,PDR6 and PDR7 proved to be the most similar proteins followed by PDR2 and PDR5 showing an amino acid identity of 82.79 and $82.49 \%$, respectively.

A phylogeny was inferred from 853 amino acid sequences of PDR proteins representing the five main fungal phyla. A simplified view of the resulting tree is shown in Figure 1 while the whole version can be found in Supplementary Figure 3. On this tree, PDR transporters of fungi belonging to the Chytridiomycota, Zoopagomycota and Mucoromycota (including the examined PDR1-8 of $M$. circinelloides) can be found in the clades, which clearly correspond to the phylogenetic position of these fungal groups. At the same time, Ascomycota and Basidiomycota sequences grouped together in various clades corresponding to different subfamilies of PDR proteins. Our results support the monophyly of Mucoromycota PDR proteins, which form a sister group of the Dicarya PDRs. Within the latter group the clade containing the $C$. neoformans Afr1 protein proved to be the closest to the Mucoromycota clade. Within the Mucoromycota clade, two main clades can be discriminated, among which the clade A contains the M. circinelloides PDR1, 6, 7 and 8 proteins while the clade B includes PDR2, 3, 4 and 5. Within the two main clades, proteins of a same species can be positioned in various subclades indicating several gene duplications and a diversification of the pdr genes in this fungal group.

\section{Relative Transcript Levels of the pdr Genes After Azole Treatment}

In general, $p d r$ genes responded differently to the tested azoles (Figure 2). Itraconazole had the widest effect on $p d r$ expression upregulating five of the eight genes, i.e., $p d r 1, p d r 2, p d r 3, p d r 5$ and $p d r 6$. Three genes ( $p d r 1, p d r 5$ and $p d r 6)$ displayed increased transcript levels in response to ketoconazole, while fluconazole treatment resulted in increased transcript level for $p d r 1, p d r 3$, $p d r 4$ and $p d r 7$. Transcript level of $p d r 1, p d r 2, p d r 3$ and $p d r 5$ increased significantly after isavuconazole treatment. From the eight genes, only $p d r 1$ had significantly increased transcript levels in response to all azoles (Figure 2). Interestingly only this gene responded with higher transcript level to posaconazole. Treatments with ketoconazole, itraconazole, fluconazole, posaconazole and ravuconazole resulted in decreased transcript levels for $p d r 7$ and $p d r 8$. Pdr4 only responded to treatment with fluconazole and ravuconazole, while the pdr6 transcript level significantly increased after ketoconazole and itraconazole treatments. A heat-map was generated to summarize the result of the qRT-PCR experiments (Figure 3). It can be seen that $p d r 1$, $p d r 3, p d r 4$ and $p d r 6$ are generally upregulated in response to azole treatments while $p d r 2, p d r 5$ and especially $p d r 7$ and $p d r 8$ are rather downregulated by the azoles.

\section{Relative Transcript Levels of pdr Genes Under Anaerobic Condition}

Morphological dimorphism is a characteristic feature of $M$. circinelloides. In the absence of oxygen, filamentous growth of the fungus switches to a yeast-like form. MS12 was grown in liquid RPMI- 1640 at $25^{\circ} \mathrm{C}$ for $24 \mathrm{~h}$. Then, the culture was transferred into an oxygen-free environment containing $10 \%$ $\mathrm{CO}_{2}$. RNA was extracted after incubating the fungus anaerobically for $240 \mathrm{~min} . P d r 1$ and $p d r 3$ displayed significantly decreased transcript levels under anaerobiosis compared to their transcript levels measured in aerobic environment (Figure 4). Contrarily, the transcript level of $p d r 5$ significantly increased under anaerobiosis (Figure 4).

\section{Knock Out of the pdr1 Gene Using the CRISPR-Cas9 Method}

Based on the qPCR experiment, deletion of $p d r 1$ gene was assigned for gene knock out by using the CRISPR-Cas9 technique. For deletion of $p d r 1$, transformation and the genome editing frequencies were $4 / 10^{5}$ protoplasts and $100 \%$, respectively, as demonstrated by PCR analysis of the isolated colonies amplifying the expected fragments (Supplementary Table 3, Supplementary Figure 4). Mutants proved to be mitotically stable retaining the integrated fragment even after 10 cultivation cycles. From the transformation experiment two

TABLE 1 | The eight identified pleiotropic drug resistance protein genes and their location in the genome of M. circinelloides.

\begin{tabular}{|c|c|c|c|c|c|c|}
\hline Protein ID & $\begin{array}{c}\text { Name } \\
\text { in this study }\end{array}$ & Location & $\begin{array}{l}\text { Amino acid } \\
\text { length }\end{array}$ & $\begin{array}{c}\text { Position of PDR/CDR } \\
\text { ABC motif }\end{array}$ & Position of NBD1 & Position of NBD2 \\
\hline 48059 & PDR1 & scaffold_03:2555182-2559793 (-) & 1416 aa & 667-805 aa & 146-151 aa & 831-837 aа \\
\hline 83305 & PDR2 & scaffold_06:2898818-2903484 (+) & 1481 aa & 737-872 aa & 217-222 aa & 898-904 aа \\
\hline 141912 & PDR3 & scaffold_04:1521204-1525513 (-) & 1415 aa & 669-807 aa & 155-160 aa & 833-839 aа \\
\hline 142239 & PDR4 & scaffold_04:2922648-2927179 (-) & 1441 aa & 698-833 aа & 183-188 aa & 859-865 aа \\
\hline 145852 & PDR5 & scaffold_06:2231882-2236192 (+) & 1371 aа & 628-763aа & 108-113 aа & 789-795 aа \\
\hline 146716 & PDR6 & scaffold_06:2892916-2897373 (+) & 1384 aa & 636-774 aa & $115-120$ aa & 800-806 aа \\
\hline 158611 & PDR7 & scaffold_01:3472584-3477196 (-) & 1463 aа & 725-863 aа & 193-198 aа & 878-884 aа \\
\hline 186086 & PDR8 & scaffold_01:475770-480189 (-) & 1349 aa & 601-739 aа & 80-85 aa & 765-771 aa \\
\hline
\end{tabular}




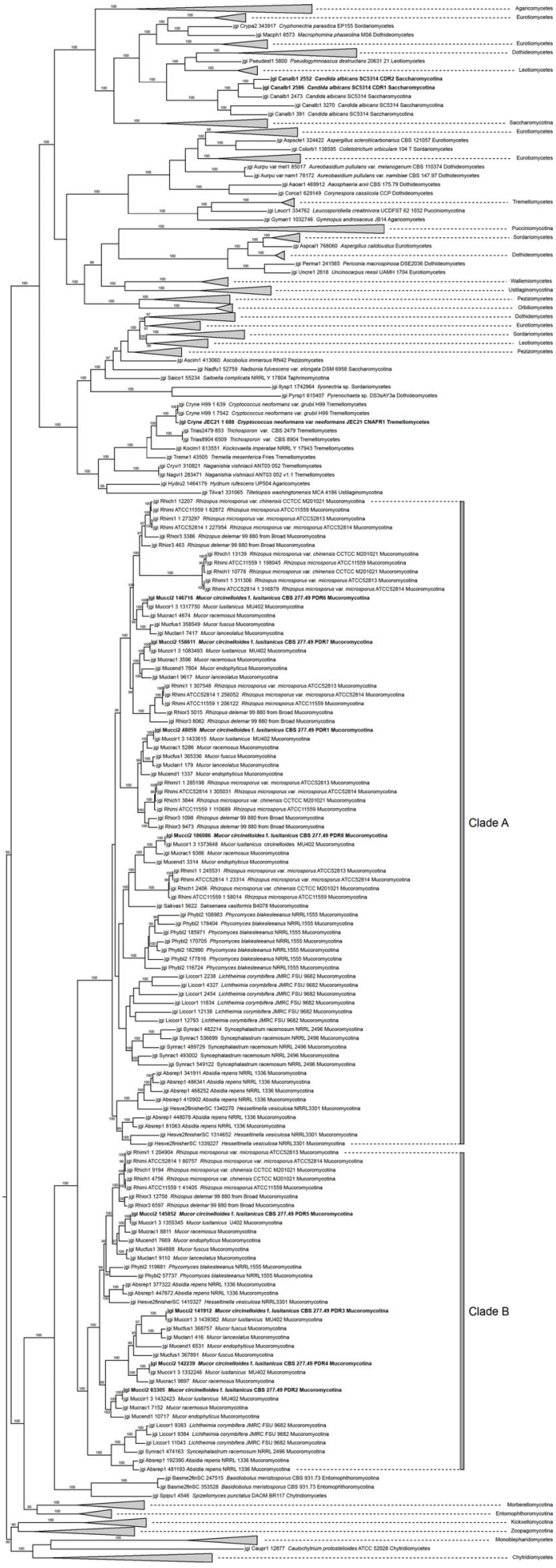

FIGURE 1 | Phylogenetic tree of PDR proteins inferred from 853 amino acid sequences using Maximum Likelihood method. The eight $M$. circinelloides Pdr proteins, C. neoformand CnAfr1 and the C. albicans Cdr1 and Cdr2 are indicated with bold characters. Numbers above or below branches are ultrafast bootstrap supports. Only values greater than 95\% are shown. isolates (MS12- $\Delta p d r 1 / 1$ and 2) were selected for the further experiments.

\section{Relative Transcript Levels of the Intact pdr Genes in the $\Delta p d r 1$ Knock Out Mutants}

qRT-PCR analysis proved the absence of the transcript of the deleted $p d r 1$ gene and revealed that the relative transcript levels of $p d r 2$ and $p d r 6$ changed significantly in the mutant (Figure 5A).

\section{Deletion of $p d r 2$ and $p d r 6$ and Creation of $\Delta p d r 1-\Delta p d r 2$ and $\Delta p d r 1-\Delta p d r 6$ Double Knock out Mutants}

Based on the qRT-PCR analysis of the MS12- $\Delta p d r 1$ mutant strain, deletion of $p d r 2$ and $p d r 6$ gene was performed using the CRISPR-Cas 9 system to create single and double mutants. For the MS12- $\Delta p d r 2$ and MS12- $\Delta p d r 6$ single mutants, transformation frequencies were 12 and 10 colonies per $10^{5}$ protoplasts, respectively while the genome editing efficiency was $83 \%$ and $100 \%$, respectively (Supplementary Table 3, Supplementary Figure 5). To create $\Delta p d r 1-\Delta p d r 2$-and $\Delta p d r 1$ $\Delta p d r 6$ double mutants, MS12- $\Delta p d r 1$ was used as the recipient strain. Transformation frequency was 8 and 3 colonies and the genome editing efficiency was $75 \%$ and $66.66 \%$ for MS12- $\Delta p d r 1$ $\Delta p d r 2$ and MS12- $\Delta p d r 1-\Delta p d r 6$, respectively (Supplementary Table 3). Two isolates from each the transformation experiments were analyzed by PCR and the expected fragments were amplified (Supplementary Figure 6).

\section{Relative Transcript Levels of the Intact $p d r$ Genes in the MS12- $\Delta p d r 2$ and MS12- $\Delta p d r 6$ Single-, and the MS12- $\Delta p d r 1-\Delta p d r 2$ and MS12- $\Delta$ pdr1- $\Delta$ pdr6 Double Knock Out Mutants}

qRT-PCR analysis proved the absence of the transcripts of the deleted genes in all mutants. It also revealed that the transcript level of $p d r 3$ and $p d r 4$ significantly decreased in the MS12- $\Delta p d r 2$ strain (Figure 5B). At the same time, deletion of the pdr6 gene led to significantly increased relative transcript levels for $p d r 1$, $p d r 7$ and $p d r 8$, while the relative transcript level of the other $p d r$ genes significantly decreased (Figure 5C).

After simultaneous deletion of $p d r 1$ and $p d r 2$, the transcript level of $p d r 8$ significantly increased in the mutants (Figure 5D). In the MS12- $\Delta p d r 1-\Delta p d r 6$ mutant, the transcript levels of $p d r 2$, $p d r 3, p d r 5, p d r 7$ significantly increased, while those of $p d r 4$ and pdr8 significantly decreased (Figure 5E).

\section{Effect of the pdr1, pdr2, and pdr6 Gene Deletions on the Colony Growth of the Mutant Strains}

Colony growth of the single (i.e., MS12- $\Delta p d r 1$, MS12- $\Delta p d r 2$ and MS12- $\Delta p d r 6$ ) and double $p d r$ mutants (i.e., MS12- $\Delta p d r 1-\Delta p d r 2$ and MS12- $\Delta p d r 1-\Delta p d r 6)$ significantly decreased compared to the parental MS12 strain on the third and fourth days of cultivation (Figure 6). When deletion of the $p d r 1$ gene was complemented by transforming pPdr1compl plasmid into the MS12- $\Delta p d r 1$ 

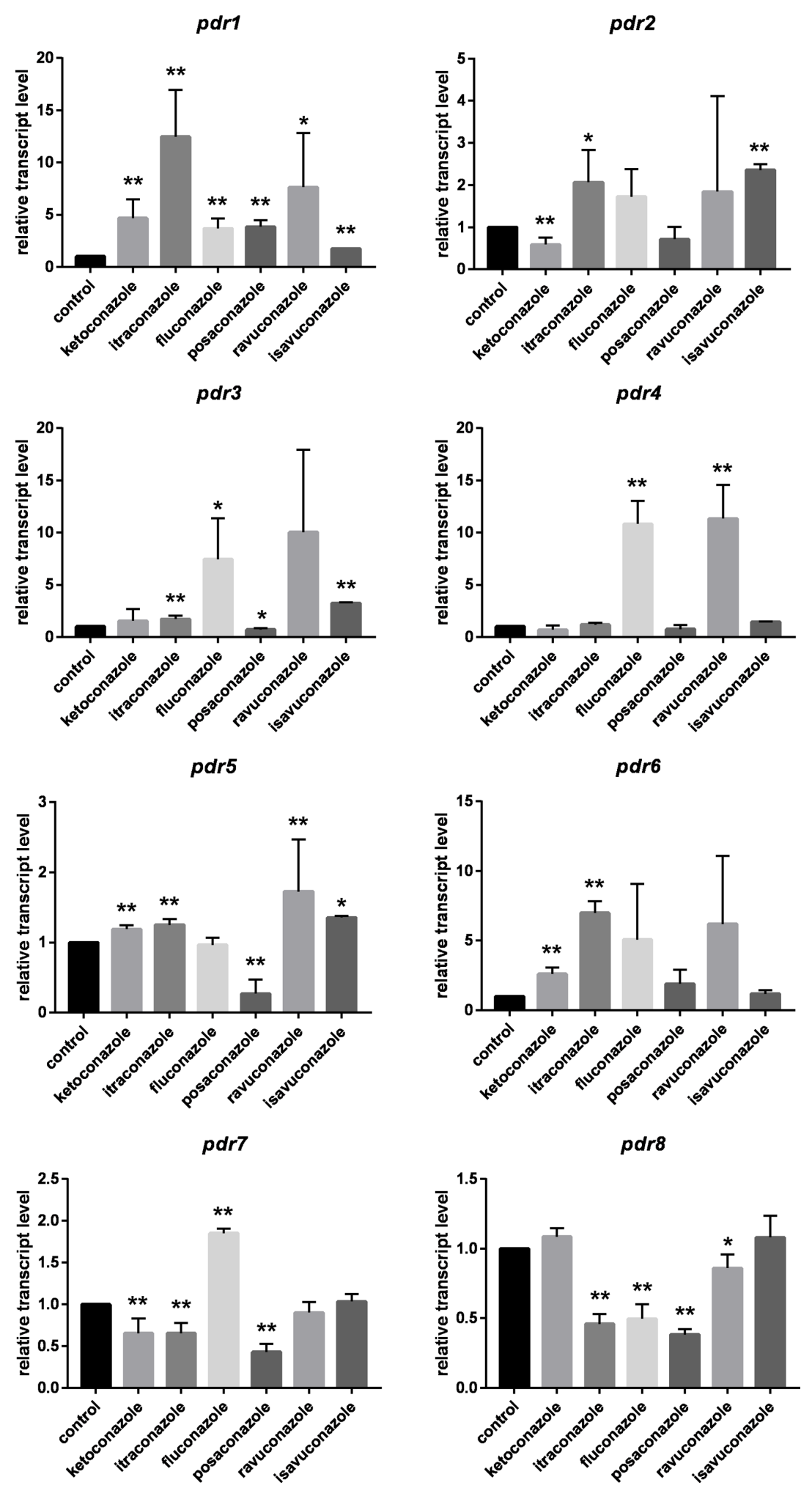

FIGURE 2 | Relative transcript levels of the pdr genes of M. circinelloides after azole treatment. MS12 was grown in RPMl-1640 liquid media at $25^{\circ} \mathrm{C}$; transcript level of each gene measured in the untreated control was taken as 1. The presented values are averages of three independent experiments; error bars indicate standard deviation. Relative transcript values followed by * and ${ }^{* \star}$ significantly differed from the untreated control according to the paired t-test $\left({ }^{*} p<0.05\right.$ and $\left.{ }^{* *} p<0.01\right)$. 


\section{control ketoconazole itraconazole fluconazole posaconazole ravuconazole isavuconazole}

\section{pdr1 pdr2 $\quad$ pdr3 $\quad$ pdr4 $\quad$ pdr5}

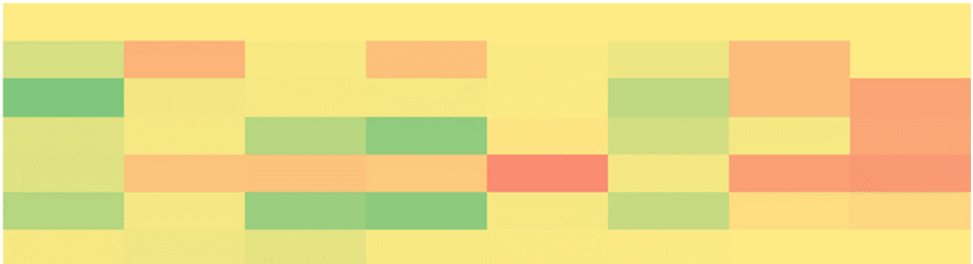

1

downregulation

upregulation

FIGURE 3 | Heat-map of transcript level of pdr genes in response to exposure to azoles. Red and green colors indicate down- and upregulation, respectively, while yellow corresponds to the transcription activity of the control.

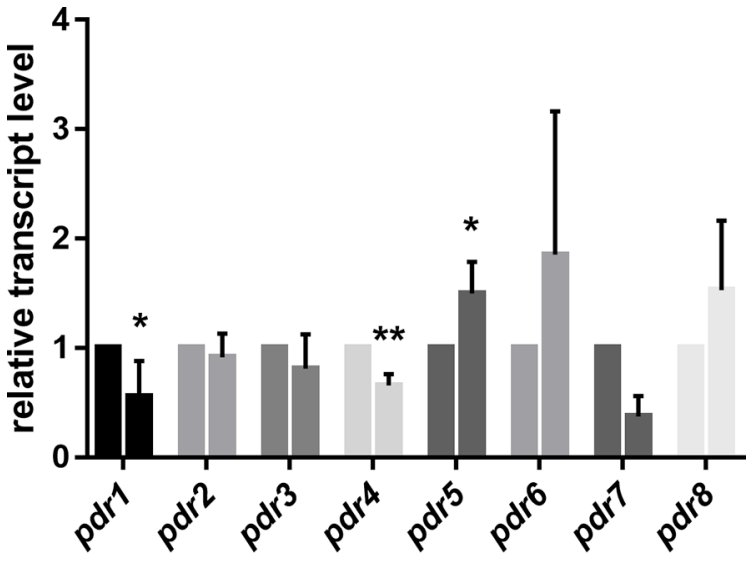

FIGURE 4 | Relative transcript levels of pdr genes under anaerobic condition. Transcript level of each gene was measured under aerobic condition was taken as 1. The presented values are averages of three independent experiments; error bars indicate standard deviation. For RNA extraction, fungal strains were cultivated on YNB for two days at $25^{\circ} \mathrm{C}$. Relative transcript values followed by * and ${ }^{* \star}$ significantly differed from the value taken as 1 according to the paired t-test $\left({ }^{*} p<0.05\right.$ and $\left.{ }^{* *} p<0,01\right)$

strain, growth ability of the resulting MS12- $\Delta p d r 1+\mathrm{pPdr} 1$ compl strain proved to be similar to that of the original MS12 strain (Figure 6A).

\section{Measurement of the R6G Efflux Activity of the Tested Strains}

To examine the drug efflux activity of the strains, R6G efflux in the parental and the $p d r$ mutant strains were compared. Twenty min after R6G uptake, MS12- $\Delta p d r 1$ and MS12- $\Delta p d r 2$ mutants showed significantly decreased efflux activity than the parental strain (Figure 7). After $30 \mathrm{~min}$, efflux activity of all mutants, except MS12- $\Delta p d r 6$, significantly decreased (Figure 7).

\section{Effect of the Gene Knock Out on the Susceptibility to Different Antifungal Agents and Hydrogen Peroxide Under Aerobic and Anaerobic Conditions}

Sensitivity of the MS12- $\Delta p d r 1$, MS12- $\Delta p d r 2$, MS12- $\Delta p d r 6$, MS12- $\Delta p d r 1-\Delta p d r 2$ and MS12- $\Delta p d r 1-\Delta p d r 6$ mutants and the MS12 strain were determined to different antifungal agents and hydrogen peroxide $\left(\mathrm{H}_{2} \mathrm{O}_{2}\right)$ by using the broth microdilution method under aerobic and anaerobic conditions and the minimal inhibitory concentration (MIC) of different azoles was determined. Sensitivity of the mutants did not differ from that of the original MS12 strain to amphotericin B, hygromycin B, terbinafine, micafungin, ketoconazole, fluconazole, cycloheximide and $\mathrm{H}_{2} \mathrm{O}_{2}$ under both aerobic and anaerobic conditions. All mutants showed, however, increased susceptibility to posaconazole and ravuconazole, while knock out of $p d r 1$ resulted in increased sensitivity to isavuconazole under anaerobic condition as well (Table 2). After complementation of the $p d r 1$ deletion, susceptibility of MS12$\Delta p d r 1+\mathrm{pPdr} 1 \mathrm{compl}$ strains to all tested azoles was similar to that of the original MS12 strain.

Under anaerobic condition, knock out of pdr2 resulted in decreased sensitivity to ketoconazole compared to the parental strain, while susceptibility of the MS12- $\Delta p d r 1$ and MS12- $\Delta p d r 2$ mutants increased to itraconazole, ravuconazole and isavuconazole. Deletion of $p d r 1$ and $p d r 2$ had no effect on the sensitivity to posaconazole under anaerobiosis. Knock out of pdr6 had no effect on the susceptibility to the different azoles at all under anaerobiosis (Table 3).

\section{DISCUSSION}

Treatment of mucormycosis is looked upon as challenging and aggravated by the fact that Mucorales species are resistant to most azole antifungals. The molecular mechanism of their innate resistance to short-tailed azoles was described, but yet not completely clarified (Caramalho et al., 2017). Resistance 
A

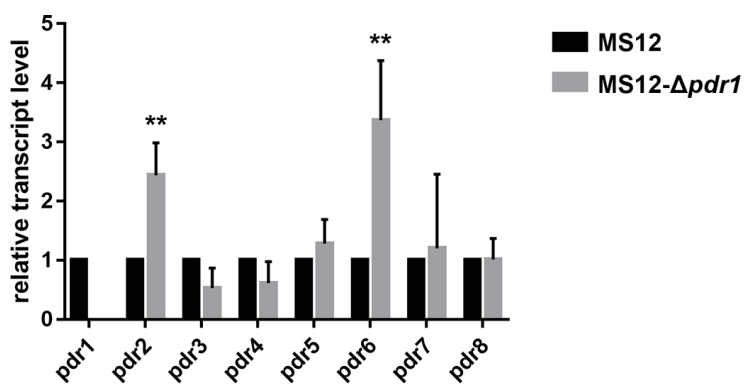

B

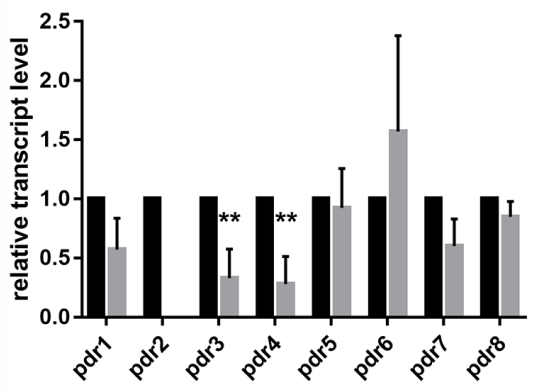

C

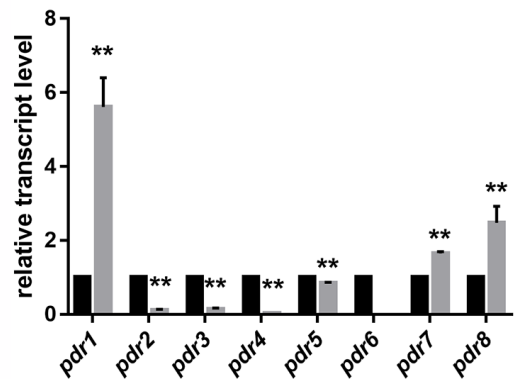

MS12

MS12- $\Delta p d r 2$

MS12

MS12- $\Delta p d r 6$
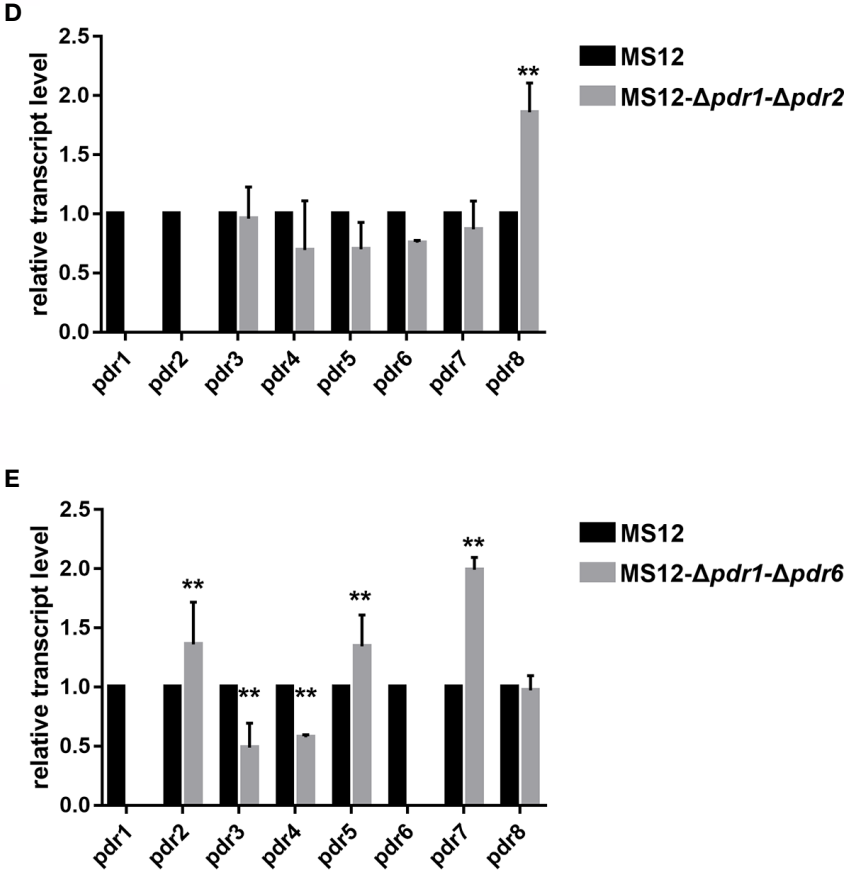

FIGURE 5 | Relative transcript levels of $p d r$ genes in the MS12- $\Delta p d r 1 / 1$ (A), MS12- $\Delta p d r 2$ (B), MS12- $\Delta p d r 6$ (C) MS12- $\Delta p d r 1-\Delta p d r 2$ (D) and MS12- $\Delta p d r 1-\Delta p d r 6$ (E) mutant compared to that in the original strain. Transcript level of each gene measured in the strain MS12 (black column) was taken as 1. The presented values are averages of three independent experiments (error bars indicate standard deviation). For RNA extraction, fungal strains were cultivated on YNB for two days at $25^{\circ} \mathrm{C}$. Relative transcript levels significantly different from the value taken as 1 according to the paired $t$-test are indicated with ${ }^{\star}$ or ${ }^{\star \star}\left({ }^{*} p<0.05,{ }^{\star \star} p<0.01\right)$.

mechanisms of various Candida and Aspergillus species have been characterized with more details (Cuenca-Estrella, 2014). The main target of azoles is the lanosterol-demethylase enzyme (i.e. Cyp51 or Erg11), which plays a crucial role in the ergosterol biosynthesis of yeasts and molds (Monk et al., 2020). Overexpression of and point mutations in the cyp51 gene can cause increased resistance to different azoles used in the clinic and agriculture (Parker et al., 2014). Besides lanosterol-demethylase, ABC- and MFS transporters are involved in the mechanism of azole resistance (Fraczek et al., 2013; Cuenca-Estrella, 2014; Gonçalves et al., 2016; Rocha et al., 2017). In C. albicans, the MFS-transporter MDR1 contribute to the fluconazole, voriconazole and ketoconazole resistance (Morschhäuser, 2010), but does not confer resistance to posaconazole, isavuconazole or itraconazole (Sanglard and Coste, 2015).
$\mathrm{ABC}$ transporters constitute one of the largest transporter superfamily. These proteins often consist of multiple subunits (i.e., of the transmembrane domain [TMD] and the nucleotide binding domain [NBD]). The transport is driven by ATP hydrolysis (Wilkens, 2015). ATP is the substrate of NBD, which has some conserved motifs, such as Walker-A, Walker$\mathrm{B}$ and the ABC-signature (Seeger and van Veen, 2009; Lamping et al., 2010; Holmes et al., 2016). The sequence of TMD is more diverse reflecting to the diversity of the transported substrate (Seeger and van Veen, 2009). Within the ABC transporters, the PDR subfamily is the most closely associated to drug resistance (Cannon et al., 2009). In the M. circinelloides genome database, eight putative PDR transporter coding genes were identified. The abovementioned motifs characteristic to $\mathrm{ABC}$ transporters were identified in each of them. 
A

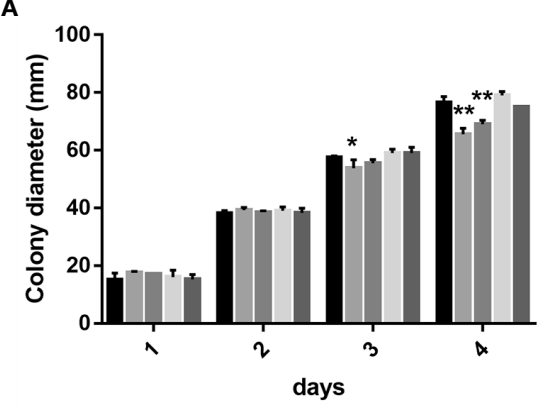

B
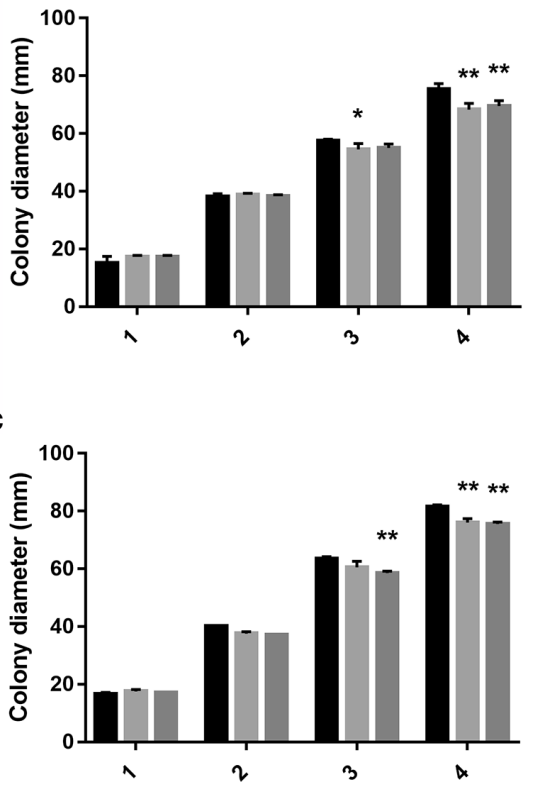

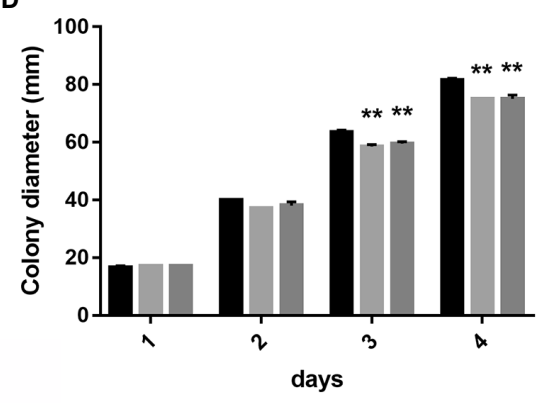

MS12

MS12- $\Delta p d r 1-\Delta p d r 2 / 1$

MS12- $\Delta p d r 1-\Delta p d r 2 / 2$

E

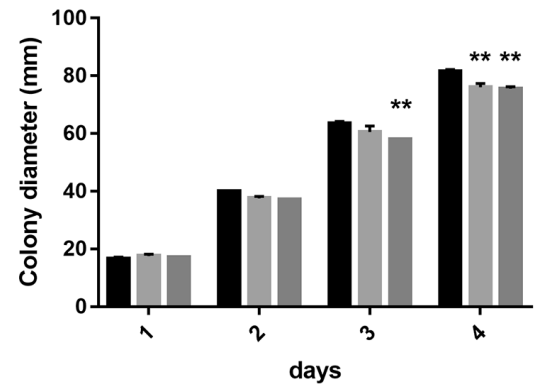

MS12

MS12- $\Delta p d r 1-\Delta p d r 6 / 1$

MS12- $\Delta p d r 1-\Delta p d r 6 / 2$

FIGURE 6 | Colony diameters of the pdr deletion mutants and the original MS12 strain of Mucor circinelloides at $25^{\circ} \mathrm{C}$ on $\mathrm{YNB}$ medium. (A) shows the colony diameter of pdr1 deleted and complemented strains, (B, C) show the colony diameter of the single pdr2 and pdr6 knock out mutants, while (D, E) show the colony diameter of the double knock out strains. The presented values are averages; colony diameters were measured during three independent cultivation (error bars indicate standard deviation). Values followed by * and ** significantly differed from the corresponding value of the MS12 strain according to the two-way Anova $\left({ }^{*} p<0.05 ;{ }^{* *} p<0.01\right)$.

Analysis of the promoter regions of the eight Mucor genes did not reveal the presence of the motifs described as PDRE (TCCG/ $\mathrm{aC/tGG/cA)}$ or CDRE (CGGA(A/T)ATCGGATATTTTTTTT) elements. These motifs were originally found and characterized in Saccharomyces (Mamnun et al., 2002) and Candida (de Micheli et al., 2002) as the binding sites of transcription factors regulating the expression of the $p d r$ genes. If such binding sites are present, the consensus sequences established for Ascomycota cannot be applied to find them, maybe because of the large evolutionary distance.

Phylogenetic analysis of PDR transporters indicated the monophyly of Mucoromycota PDRs; although, within the Mucoromycota clade various gene duplication events can be assumed. Based on a phylogenetic analysis of 78 PDR proteins, Lamping et al. (2010) previously discerned 10 clades of PDR transporters within the Dicarya, among which four clades (i.e. clades B, G, H1a and H1b) contained PDRs of both Ascomycota and Basidiomycota fungi. None of the involved Mucoromycota sequences grouped together with any of the Dikarya PDRs.

Mucor $p d r$ genes show similarity to the C. neoformans Afr 1 gene, which was also strengthen by the phylogenetic analysis of the fungal PDR genes Afrl is involved in the resistance of Cryptococcus to fluconazole (Sanguinetti et al., 2006). Overexpression of Afr 1 increased the azole resistance indicating that upregulation of the gene may play a role in the fluconazole resistance (Posteraro et al., 2003; Sanguinetti et al., 2006; Morschhäuser, 2010). In our experiments, transcription level of all $M$. circinelloides $p d r$ genes altered after treatment with either of the tested azoles, although only that of the $p d r 1$ increased in response to all of them.

Mucorales species are generally resistant to fluconazole and voriconazole, while isavuconazole and itraconazole were found to have in vitro species-specific activity (Dannaoui, 2017). International guidelines for the treatment of mucormycosis 


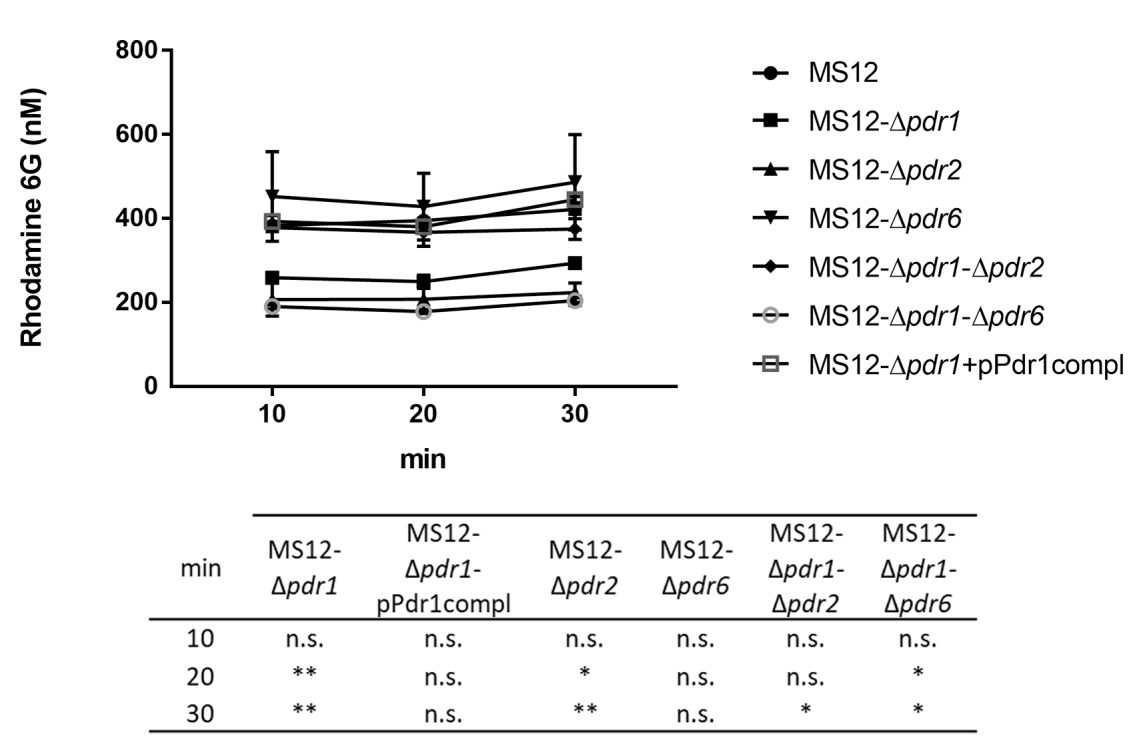

FIGURE 7 | Measurement of the R6G efflux activity. After uptake of rhodamine 6G, fungal cells were resuspended in PBS supplemented with 2 nM of D-glucose. Values followed by * and ${ }^{* *}$ significantly differed from the corresponding value of the MS12 strain according to the two-way Anova ( ${ }^{*} p<0.05$; ${ }^{* *} p<0.01$ ), n.s. is non-significant.

TABLE 2 | Minimal inhibitory concentrations (MIC) of the azoles $(\mu \mathrm{g} / \mathrm{ml})$ against the mutants and the parental M. circinelloides MS12 strain under aerobic condition.

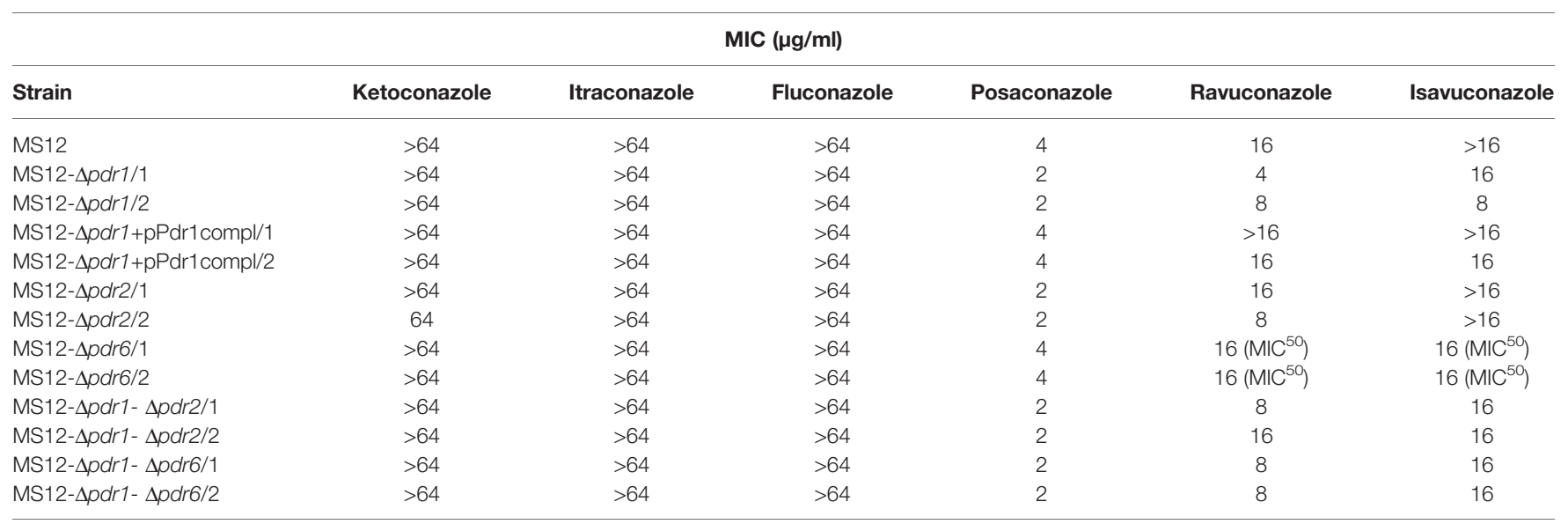

suggest first-line antifungal therapy with lipid formulations of amphotericin B (AMB), whereas posaconazole (Cornely et al., 2014) is recommended and isavuconazole (Ashkenazi-Hoffnung et al., 2020) was successfully used as salvage therapy. In our study, posaconazole treatment affected the transcription of $p d r 1$ only while isavuconazole significantly increased the transcript level of $p d r 1, p d r 2, p d r 3$ and $p d r 5$.

Deletion of $p d r 1$ increased the sensitivity of the mutants to posaconazole and isavuconazole. Although it was found to be upregulated by isavuconazole, deletion of $p d r 2$ did not affect the susceptibility to this compound. At the same time, MS12- $\Delta p d r 2$ mutants showed increased susceptibility to posaconazole similarly to the MS12- $\Delta p d r 1$ strains.

Fluconazole treatment affected the transcription of various genes including pdr1 but neither single nor double deletion mutants generated in this study displayed altered susceptibility to this drug. This result is in agreement with the observations that, in addition to active transport mechanisms, alterations in the lanosterol-demethylase gene (Edlind et al., 2001; Sionov et al., 2012; Leonardelli et al., 2016; Caramalho et al., 2017) and/or a novel Zn2-Cys6 transcription factor may also underlie the fluconazole resistance of these fungi (Hagiwara et al., 2017).

qRT-PCR analysis revealed highly similar transcription patterns for $p d r 1$ and $p d r 6$ after azole treatment. At the same time, deletion of $p d r 1$ caused significantly increased transcript level of $p d r 2$ and $p d r 6$, while the relative transcript level of $p d r 1$, $p d r 7$ and $p d r 8$ significantly increased in the MS12- $\Delta p d r 6$ mutant. These results suggest that regulation of $p d r$ genes is highly interconnected and coordinated. It can also be assumed that the increased activity of certain $p d r$ genes may compensate the 
TABLE 3 | Minimal inhibitory concentrations (MIC) of the azoles $(\mu \mathrm{g} / \mathrm{mll})$ against the transformants and the parental $M$. circinelloides MS12 strain under anaerobic condition.

\begin{tabular}{|c|c|c|c|c|c|c|}
\hline \multicolumn{7}{|c|}{ MIC ( $\mu \mathrm{g} / \mathrm{ml})$} \\
\hline Strain & Ketoconazole & Itraconazole & Fluconazole & Posaconazole & Ravuconazole & Isavuconazole \\
\hline MS12 & 32 & 4 & $>64$ & 2 & 4 & 4 \\
\hline MS12- $\Delta p d r 1 / 1$ & 32 & 2 & $>64$ & 2 & 2 & 2 \\
\hline MS12- $\Delta p d r 1 / 2$ & 32 & 2 & $>64$ & 2 & 2 & 2 \\
\hline MS12- $\Delta p d r 1+p P d r 1 c o m p l / 1$ & 32 & 4 & $>64$ & 2 & 4 & 4 \\
\hline MS12-spdr1+pPdr1compl/1 & 32 & 4 & $>64$ & 2 & 2 & 2 \\
\hline MS12- $\Delta p d r 2 / 1$ & 64 & 2 & $>64$ & 2 & 2 & 4 \\
\hline MS12- $\Delta p d r 2 / 2$ & 64 & 2 & $>64$ & 1 & 2 & 2 \\
\hline MS12- $\Delta p d r 6 / 1$ & 32 & 4 & $>64$ & 2 & 4 & 4 \\
\hline MS12- $\Delta p d r 6 / 2$ & 32 & 4 & $>64$ & 2 & 4 & 4 \\
\hline MS12- $\Delta p d r 1-\Delta p d r 2 / 1$ & 32 & 2 & $>64$ & 2 & 2 & 2 \\
\hline MS12- $\Delta p d r 1-\Delta p d r 2 / 2$ & 32 & 2 & $>64$ & 2 & 2 & 2 \\
\hline MS12- $\Delta p d r 1-\Delta p d r 6 / 1$ & 64 & 2 & $>64$ & 2 & 2 & 4 \\
\hline MS12- $\Delta p d r 1-\Delta p d r 6 / 2$ & 64 & 2 & $>64$ & 1 & 2 & 2 \\
\hline
\end{tabular}

lack of the deleted genes. A similar phenomenon was previously described for the three HMG-CoA reductase isogenes in $M$. circinelloides (Nagy et al., 2019). Functional linkages of genes involved in antifungal resistance was observed in Saccharomyces cerevisiae where deletion of two multidrug transporter genes, yor 1 and snq 2 caused an increased expression of $p d r 5$, while the lack of pdr5 and snq2 induced yor 1 expression (Kolaczkowska et al., 2008).

Susceptibility testing of the deletion mutants suggests that $p d r 1$ and $p d r 2$ may have role in the protection from the effect of posaconazole, isavuconazole and ravuconazole and this function is affected by the oxygen level of the environment. At the same time, deletion of pdr6 had no significant effect on the azole resistance of the fungus. Deletion of $p d r 1$ and $p d r 2$ resulted decreased efflux activity in all tested mutant strains, while the efflux activity of MS12- $\Delta p d r 6$ strain was similar to the parental MS12 strain.

Our results suggest that the tested $p d r$ genes involved in different degrees in the resistance to the different azoles. In $C$. glabrata Cdr1 and Cdr2 also had a different effect on the resistance to azoles (Sanglard et al., 2001). In A. fumigatus deletion of $a b c A$ and $a b c B / c d r 1 B$ transporters, which show the highest similarity to $S$. cerevisiae $p d r 5$, resulted in increased susceptibility to voriconazole, but this effect was more pronounced in case of the $\Delta a b c B / c d r 1 B$ mutant (Paul et al., 2013). In Aspergillus oryzae, deletion of atrG belonging to the PDR subfamily, caused increased azole susceptibility, while its simultaneous deletion with atrA conferred azole hypersensitivity (Miura et al., 2018).

In the absence of oxygen, filamentous growth of $M$. circinelloides switches to a yeast-like form and the fungus produces energy by fermentation (Nagy et al., 2014). These morphological and metabolic changes are necessary associated to serious changes in the expression of numerous genes. Transporters and other membrane associated proteins are expected to be affected by these processes. Under anaerobic condition, the transcript levels of $p d r 1$ and $p d r 4$ decreased, while the transcript level of pdr5 increased significantly compared to the aerobic condition. The transcript levels of other $p d r$ genes did not change significantly. The growth ability of the created mutants somewhat decreased compared to the parental strain. This phenomenon can be explained by the fact that the function of PDR transporters in not limited to the drug export. In S. cerevisiae Aus1p and Pdr11p are required for import of exogenous sterols for anaerobic growth (Wilcox et al., 2002; Reiner et al., 2006; Kohut et al., 2011; Zavrel et al., 2013) and simultaneous disruption of the encoding genes proved to be lethal under anaerobiosis (Wilcox et al., 2002). S. cerevisiae Pdr5 and Yor1 play role in the externalization of lipids (Decottignies et al., 1998; Pomorski et al., 2003). In C. albicans, Cdr1 plays role in the drug efflux and, along with Cdr2 and Cdr3, involved in the externalization of lipids (Smriti et al., 2002; Tsao et al., 2009).

\section{CONCLUSION}

M. circinelloides has eight genes encoding PDR transporters. Transcription analysis of these genes suggests that their regulation is interconnected and affected by the different azoles. The genes $p d r 1$ and $p d r 2$ seem to participate in the resistance or reduced sensitivity to posaconazole, ravuconazole and isavuconazole. It is also clear, that resistance to these azoles and azole resistance in general cannot be completely explained by the activity of the tested PDR proteins. Other mechanisms, such as special regulatory processes, multiple transporter genes and alterations in the lanosterol-demethylase gene might also be involved.

\section{DATA AVAILABILITY STATEMENT}

The original contributions presented in the study are included in the article/Supplementary Material. Further inquiries can be directed to the corresponding author. 


\section{AUTHOR CONTRIBUTIONS}

GN (1st Author) and TP designed the approach and the experiments, participated in the experimental work, managed the study, and wrote the manuscript. SKi, RV, KB, CS, HM, ZN, and GN (10th Author) participated in the experimental work. SKo, LB, and CV participated in the data analysis, evaluation of the results and drafting the manuscript. All authors contributed to the article and approved the submitted version.

\section{FUNDING}

This study was supported by the "Lendület" Grant of the Hungarian Academy of Sciences (LP2016-8/2016), the project

\section{REFERENCES}

Alcalde, E., Cerdá-Olmedo, E., and Al-Babili, S. (2019). Apocarotenoids produced from $\beta$-carotene by dioxygenases from Mucor circinelloides. Microbiology 165, 433-438. doi: 10.1128/AAC.00452-07

Almyroudis, N. G., Sutton, D. A., Fothergill, A. W., Rinaldi, M. G., and Kusne, S. (2007). In vitro susceptibilities of 217 clinical isolates of zygomycetes to conventional and new antifungal agents. Antimicrob. Agents Chemother. 51, 2587-2590. doi: 10.1128/AAC.00452-07

Ashkenazi-Hoffnung, L., Bilavsky, E., Levy, I., Grisaru, G., Sadot, E., Ben-Ami, R., et al. (2020). Isavuconazole As Successful Salvage Therapy for Mucormycosis in Pediatric Patients. Pediatr. Infect. Dis. J. 39, 718-724. doi: 10.1097/ INF.0000000000002671

Bakr, A., Wafa, E., Fouda, A., Elagroudy, A., Gheith, O., Sobh, M., et al. (2008). Successful treatment of mucormycosis in a renal allograft recipient. Clin. Exp. Nephrol. 12, 207-210. doi: 10.1007/s10157-008-0028-7

Benito, E. P., Díaz-Mínguez, J. M., Iturriaga, E. A., Campuzano, V., and Eslava, A. P. (1992). Cloning and sequence analysis of the Mucor circinelloides pyrG gene encoding orotidine-5'-monophosphate decarboxylase: use of pyrG for homologous transformation. Gene 116, 59-67. doi: 10.1016/0378-1119(92) 90629-4

Calo, S., Nicolás, F. E., Lee, S. C., Vila, A., Cervantes, M., Torres-Martinez, S., et al. (2017). A non-canonical RNA degradation pathway suppresses RNAidependent epimutations in the human fungal pathogen Mucor circinelloides. PloS Genet. 13, e1006686. doi: 10.1371/journal.pgen.1006686

Cannon, R. D., Lamping, E., Holmes, A. R., Niimi, K., Baret, P. V., Keniya, M. V., et al. (2009). Efflux-mediated antifungal drug resistance. Clin. Microbiol. Rev. 22, 291-321. doi: 10.1128/CMR.00051-08

Capella-Gutiérrez, S., Silla-Martínez, J. M., and Gabaldón, T. (2009). trimAl: a tool for automated alignment trimming in large-scale phylogenetic analyses. Bioinformatics 25, 1972-1973. doi: 10.1093/bioinformatics/btp348

Caramalho, R., Tyndall, J. D. A., Monk, B. C., Larentis, T., Lass-Flörl, C., and Lackner, M. (2017). Intrinsic short-tailed azole resistance in mucormycetes is due to an evolutionary conserved aminoacid substitution of the lanosterol $14 \alpha-$ demethylase. Sci. Rep. 7, 15898. doi: 10.1038/s41598-017-16123-9

Chang, M., Sionov, E., Khanal Lamichhane, A. K., Kwon-Chung, K. J., and Chang, Y. C. (2018). Roles of three Cryptococcus neoformans and Cryptococcus gattii efflux pump-coding genes in response to drug treatment. Antimicrob. Agents Chemother. 62, e01751-17. doi: 10.1128/AAC.01751-17

Cornely, O. A., Arikan-Akdagli, S., Dannaoui, E., Groll, A. H., Lagrou, K., Chakrabarti, A., et al. (2014). ESCMID and ECMM joint clinical guidelines for the diagnosis and management of mucormycosis 2013. Clin. Microbiol. Infect. 20 Suppl 3, 5-26. doi: 10.1111/1469-0691.12371

Corrochano, L. M., and Garre, V. (2010). Photobiology in the Zygomycota: multiple photoreceptor genes for complex responses to light. Fungal Genet. Biol. 47, 893-899. doi: 10.1016/j.fgb.2010.04.007

Corrochano, L. M., Kuo, A., Marcet-Houben, M., Polaino, S., Salamov, A., Villalobos-Escobedo, J. M., et al. (2016). Expansion of Signal Transduction
GINOP-2.3.2-15-2016-00035 and the NKFI project K131796. GN is grateful for support of the Premium Postdoctoral Fellowship Program of the Hungarian Academy of Sciences (460050). LB was supported by the János Bolyai Research Scholarship (BO/00522/19/8) of the Hungarian Academy of Sciences.

\section{SUPPLEMENTARY MATERIAL}

The Supplementary Material for this article can be found online at: https://www.frontiersin.org/articles/10.3389/fcimb.2021. 660347/full\#supplementary-material

Pathways in Fungi by Extensive Genome Duplication. Curr. Biol. 26, $1577-$ 1584. doi: 10.1016/j.cub.2016.04.038

Cowen, L. E., Sanglard, D., Howard, S. J., Rogers, P. D., and Perlin, D. S. (2015). Mechanisms of antifungal drug resistance. Cold Spring Harbor Perspect. Med. 5, 1-22. doi: 10.1101/cshperspect.a019752

Cuenca-Estrella, M. (2014). Antifungal drug resistance mechanisms in pathogenic fungi: from bench to bedside. Clin. Microbiol. Infect. 20, 54-59. doi: 10.1111/ 1469-0691.12495

Dannaoui, E. (2017). Antifungal resistance in mucorales. Int. J. Antimicrob. Agents 50, 617-621. doi: 10.1016/j.ijantimicag.2017.08.010

de Micheli, M., Bille, J., Schueller, C., and Sanglard, D. (2002). A common drugresponsive element mediates the upregulation of the Candida albicans $\mathrm{ABC}$ transporters Cdr1 and Cdr2, two genes involved in antifungal drug resistance. Mol. Microbiol. 43, 1197-1214. doi: 10.1046/j.1365-2958.2002.02814.x

Decottignies, A., Grant, A. M., Nichols, J. W., de Wet, H., McIntosh, D. B., and Goffeau, A. (1998). ATPase and multidrug transport activities of the overexpressed yeast ABC protein Yor1p. J. Biol. Chem. 273, 12612-12622. doi: $10.1074 /$ jbc. 273.20 .12612

Drogari-Apiranthitou, M., Mantopoulou, F.-D., Skiada, A., Kanioura, L., Grammatikou, M., Vrioni, G., et al. (2012). In vitro antifungal susceptibility of filamentous fungi causing rare infections: synergy testing of amphotericin B, posaconazole and anidulafungin in pairs. J. Antimicrob. Chemother. 67, 19371940. doi: $10.1093 / \mathrm{jac} / \mathrm{dks} 137$

Edlind, T. D., Henry, K. W., Metera, K. A., and Katiyar, S. K. (2001). Aspergillus fumigatus CYP51 sequence: potential basis for fluconazole resistance. Med. Mycol. 39, 299-302. doi: 10.1080/mmy.39.3.299.302

Fraczek, M. G., Bromley, M., Buied, A., Moore, C. B., Rajendran, R., Rautemaa, R., et al. (2013). The cdr1B efflux transporter is associated with non-cyp51amediated itraconazole resistance in Aspergillus fumigatus. J. Antimicrob. Chemother. 68, 1486-1496. doi: 10.1093/jac/dkt075

Gasteiger, E., Hoogland, C., Gattiker, A., Duvaud, S., Wilkins, M. R., Appel, R. D., et al. (2005). "Protein Identification and Analysis Tools on the ExPASy Server," in The Proteomics Protocols Handbook Springer Protocols Handbooks., ed. J. M. Walker (Totowa, NJ: Humana Press), 571-607. doi: 10.1385/1-59259-890$0: 571$

Gauthier, C., Weber, S., Alarco, A.-M., Algawi, O., Daoud, R., Georges, E., et al. (2003). Functional Similarities and Differences between Candida albicans Cdr1p and Cdr2p Transporters. Antimicrob. Agents Chemother. 47, 15431554. doi: 10.1128/AAC.47.5.1543-1554.2003

Gbelska, Y., Toth Hervay, N., Dzugasova, V., and Konecna, A. (2017). Measurement of Energy-dependent Rhodamine 6G Efflux in Yeast Species. Bio-protocol 7, e2428. doi: 10.21769/BioProtoc. 2428

Gonçalves, S. S., Souza, A. C. R., Chowdhary, A., Meis, J. F., and Colombo, A. L. (2016). Epidemiology and molecular mechanisms of antifungal resistance in Candida and Aspergillus. Mycoses 59, 198-219. doi: 10.1111/myc.12469

Grigoriev, I. V., Nikitin, R., Haridas, S., Kuo, A., Ohm, R., Otillar, R., et al. (2014). MycoCosm portal: gearing up for 1000 fungal genomes. Nucleic Acids Res. 42, 699-704. doi: 10.1093/nar/gkt1183 
Hagiwara, D., Miura, D., Shimizu, K., Paul, S., Ohba, A., Gonoi, T., et al. (2017). A Novel Zn2-Cys6 Transcription Factor AtrR Plays a Key Role in an Azole Resistance Mechanism of Aspergillus fumigatus by Co-regulating cyp51A and cdr1B Expressions. PloS Pathog. 13, e1006096. doi: 10.1371/journal.ppat.1006096

Higgins, D. G., Thompson, J. D., and Gibson, T. J. (1996). Using CLUSTAL for multiple sequence alignments. Methods Enzymol. 266, 383-402. doi: 10.1016/ s0076-6879(96)66024-8

Hoang, D. T., Chernomor, O., von Haeseler, A., Minh, B. Q., and Vinh, L. S. (2018). UFBoot2: Improving the ultrafast bootstrap approximation. Mol. Biol. Evol. 35, 518-522. doi: 10.1093/molbev/msx281

Hoffmann, K., Pawłowska, J., Walther, G., Wrzosek, M., de Hoog, G. S., Benny, G. L., et al. (2013). The family structure of the Mucorales: a synoptic revision based on comprehensive multigene-genealogies. Persoonia 30, 57-76. doi: 10.3767/003158513X666259

Holmes, A. R., Cardno, T. S., Strouse, J. J., Ivnitski-Steele, I., Keniya, M. V., Lackovic, K., et al. (2016). Targeting efflux pumps to overcome antifungal drug resistance. Future Med. Chem. 8, 1485-1501. doi: 10.4155/fmc-2016-0050

Ibrahim, A. S., Spellberg, B., Walsh, T. J., and Kontoyiannis, D. P. (2012). Pathogenesis of Mucormycosis. Clin. Infect. Dis. 54, S16-S22. doi: 10.1093/ $\mathrm{cid} / \mathrm{cir} 865$

Jeong, W., Keighley, C., Wolfe, R., Lee, W. L., Slavin, M. A., Kong, D. C. M., et al. (2019). The epidemiology and clinical manifestations of mucormycosis: a systematic review and meta-analysis of case reports. Clin. Microbiol. Infect. 25, 26-34. doi: 10.1016/j.cmi.2018.07.011

Kalyaanamoorthy, S., Minh, B. Q., Wong, T. K. F., von Haeseler, A., and Jermiin, L. S. (2017). ModelFinder: fast model selection for accurate phylogenetic estimates. Nat. Methods 14, 587-589. doi: 10.1038/nmeth.4285

Katoh, K., and Standley, D. M. (2013). MAFFT multiple sequence alignment software version 7: improvements in performance and usability. Mol. Biol. Evol. 30, 772-780. doi: 10.1093/molbev/mst010

Kohut, P., Wüstner, D., Hronska, L., Kuchler, K., Hapala, I., and Valachovic, M. (2011). The role of ABC proteins Aus1p and Pdr11p in the uptake of external sterols in yeast: Dehydroergosterol fluorescence study. Biochem. Biophys. Res. Commun. 404, 233-238. doi: 10.1016/j.bbrc.2010.11.099

Kolaczkowska, A., Kolaczkowski, M., Goffeau, A., and Moye-Rowley, W. S. (2008). Compensatory activation of the multidrug transporters Pdr5p, Snq2p, and Yorlp by Pdrlp in Saccharomyces cerevisiae. FEBS Lett. 582, 977-983. doi: 10.1016/j.febslet.2008.02.045

Lamping, E., Baret, P. V., Holmes, A. R., Monk, B. C., Goffeau, A., and Cannon, R. D. (2010). Fungal PDR transporters: Phylogeny, topology, motifs and function. Fungal Genet. Biol. 47, 127-142. doi: 10.1016/j.fgb.2009.10.007

Lax, C., Pérez-Arques, C., Navarro-Mendoza, M. I., Cánovas-Márquez, J. T., Tahiri, G., Pérez-Ruiz, J. A., et al. (2020). Genes, pathways, and mechanisms involved in the virulence of Mucorales. Genes 11, 317. doi: 10.3390/ genes 11030317

Lee, S. C., Li, A., Calo, S., Inoue, M., Tonthat, N. K., Bain, J. M., et al. (2015). Calcineurin orchestrates dimorphic transitions, antifungal drug responses and host-pathogen interactions of the pathogenic mucoralean fungus Mucor circinelloides. Mol. Microbiol. 97, 844-865. doi: 10.1111/mmi.13071

Leonardelli, F., Macedo, D., Dudiuk, C., Cabeza, M. S., Gamarra, S., and GarciaEffron, G. (2016). Aspergillus fumigatus Intrinsic Fluconazole Resistance Is Due to the Naturally Occurring T301I Substitution in Cyp51Ap. Antimicrob. Agents Chemother. 60, 5420-5426. doi: 10.1128/AAC.00905-16

Li, C. H., Cervantes, M., Springer, D. J., Boekhout, T., Ruiz-Vazquez, R. M., Torres-Martinez, S. R., et al. (2011). Sporangiospore size dimorphism is linked to virulence of Mucor circinelloides. PloS Pathog. 7, e1002086. doi: 10.1371/ journal.ppat.1002086

Livak, K. J., and Schmittgen, T. D. (2001). Analysis of relative gene expression data using real-time quantitative PCR and the 2(-Delta Delta $\mathrm{C}(\mathrm{T})$ ) Method. Methods 25, 402-408. doi: 10.1006/meth.2001.1262

López-Fernández, L., Sanchis, M., Navarro-Rodríguez, P., Nicolás, F. E., SilvaFranco, F., Guarro, J., et al. (2018). Understanding Mucor circinelloides pathogenesis by comparative genomics and phenotypical studies. Virulence 9, 707-720. doi: 10.1080/21505594.2018.1435249

Lopez-Ribot, J. L., Wiederhold, N. P., and Patterson, T. F. (2017). "Fungal Drug Resistance: Azoles," in Antimicrobial Drug Resistance, eds. D. L. Mayers, J. D. Sobel, M. Ouellette, K. S. Kaye and D. Marchaim (Cham: Springer International Publishing), 397-405. doi: 10.1007/978-3-319-46718-4_27
Mamnun, Y. M., Pandjaitan, R., Mahé, Y., Delahodde, A., and Kuchler, K. (2002). Thw yeast zinc finger regulators Pdrlp and Pdr3p control pleiotropic drug resistance (PDR) as homo- and heterodimers in vivo. Mol. Microbiol. 45, 14291440. doi: 10.1046/j.1365-2958.2002.03262.x

Miura, D., Sugiyama, K., Ito, A., Ohba-Tanaka, A., Tanaka, M., Shintani, T., et al. (2018). The PDR-type ABC transporters AtrA and AtrG are involved in azole drug resistance in Aspergillus oryzae. Biosci. Biotechnol. Biochem. 82, 18401848. doi: 10.1080/09168451.2018.1497941

Monk, B. C., Sagatova, A. A., Hosseini, P., Ruma, Y. N., Wilson, R. K., and Keniya, M. V. (2020). Fungal Lanosterol $14 \alpha$-demethylase: A target for next-generation antifungal design. Biochim. Biophys. Acta (BBA) - Proteins Proteomics 1868, 140206. doi: 10.1016/j.bbapap.2019.02.008

Moriwaki-Takano, M., Iwakura, R., and Hoshino, K. (2020). Dimorphic mechanism on cAMP mediated signal pathway in Mucor circinelloides. Appl. Biochem. Biotechnol. doi: 10.1007/s12010-020-03342-6

Morschhäuser, J. (2010). Regulation of multidrug resistance in pathogenic fungi. Fungal Genet. Biol. 47, 94-106. doi: 10.1016/j.fgb.2009.08.002

Nagy, Á., Vágvölgyi, CS., Balla, É., and Ferenczy, L. (1994). Electrophoretic karyotype of Mucor circinelloides. Curr. Genet. 26, 45-48. doi: 10.1007/ BF00326303

Nagy, G., Farkas, A., Csernetics, Á., Bencsik, O., Szekeres, A., Nyilasi, I., et al. (2014). Transcription of the three HMG-CoA reductase genes of Mucor circinelloides. BMC Microbiol. 14:93. doi: 10.1186/1471-2180-14-93

Nagy, G., Szebenyi, C., Csernetics, Á., Vaz, A. G., Tóth, E. J., Vágvölgyi, C., et al. (2017). Development of a plasmid free CRISPR-Cas9 system for the genetic modification of Mucor circinelloides. Sci. Rep. 7, 16800. doi: 10.1038/s41598017-17118-2

Nagy, G., Vaz, A. G., Szebenyi, C., Takó, M., Tóth, E. J., Csernetics, Á., et al. (2019). CRISPR-Cas9-mediated disruption of the HMG-CoA reductase genes of Mucor circinelloides and subcellular localization of the encoded enzymes. Fungal Genet. Biol. 129, 30-39. doi: 10.1016/j.fgb.2019.04.008

Navarro, E., Niemann, N., Kock, D., Dadaeva, T., Gutiérrez, G., Engelsdorf, T., et al. (2020). The DASH-type cryptochrome from the fungus Mucor circinelloides is a canonical CPD-photolyase. Curr. Biol. 30, 4483-4490. doi: 10.1016/j.cub.2020.08.051

Nguyen, L-T., Schmidt, H. A., von Haeseler, A., and Minh, B. Q. (2015). IQ-TREE: A fast and effective stochastic algorithm for estimating maximum likelihood phylogenies. Mol. Biol. Evol. 32, 268-274. doi: 10.1093/molbev/msu300

Odds, F. C., Brown, A. J. P., and Gow, N. A. R. (2003). Antifungal agents: mechanisms of action. Trends Microbiol. 11, 272-279. doi: 10.1016/s0966-842x (03)00117-3

Pagni, M., Ioannidis, V., Cerutti, L., Zahn-Zabal, M., Jongeneel, C. V., Hau, J., et al. (2007). MyHits: improvements to an interactive resource for analyzing protein sequences. Nucleic Acids Res. 35, 433-437. doi: 10.1093/nar/gkm352

Parker, J. E., Warrilow, A. G. S., Price, C. L., Mullins, J. G. L., Kelly, D. E., and Kelly, S. L. (2014). Resistance to antifungals that target CYP51. J. Chem. Biol. 7, 143-161. doi: 10.1007/s12154-014-0121-1

Patiño-Medina, J. A., Reyes-Mares, N. Y., Valle-Maldonado, M. I., JácomeGalarza, I. E., Pérez-Arques, C., Nuñez-Anita, R. E., et al. (2019). Heterotrimeric G-alpha subunits Gpa11 and Gpa12 define a transduction pathway that control spore size and virulence in Mucor circinelloides. PloS One 14, e0226682. doi: 10.1371/journal.pone.0226682

Paul, S., Diekema, D., and Moye-Rowley, W. S. (2013). Contributions of Aspergillus fumigatus ATP-Binding Cassette Transporter Proteins to Drug Resistance and Virulence. Eukaryot Cell 12, 1619-1628. doi: 10.1128/ EC.00171-13

Pomorski, T., Lombardi, R., Riezman, H., Devaux, P. F., van Meer, G., and Holthuis, J. C. M. (2003). Drs2p-related P-type ATPases Dnflp and Dnf2p are required for phospholipid translocation across the yeast plasma membrane and serve a role in endocytosis. Mol. Biol. Cell 14, 1240-1254. doi: 10.1091/mbc.e02-08-0501

Posteraro, B., Sanguinetti, M., Sanglard, D., Sorda, M. L., Boccia, S., Romano, L., et al. (2003). Identification and characterization of a Cryptococcus neoformans ATP binding cassette (ABC) transporter-encoding gene, CnAFR1, involved in the resistance to fluconazole. Mol. Microbiol. 47, 357-371. doi: 10.1046/j.13652958.2003.03281.x

Prabhu, R. M., and Patel, R. (2004). Mucormycosis and entomophthoramycosis: a review of the clinical manifestations, diagnosis and treatment. Clin. Microbiol. Infect. 10 Suppl 1, 31-47. doi: 10.1111/j.1470-9465.2004.00843.x 
Prakash, H., and Chakrabarti, A. (2019). Global Epidemiology of Mucormycosis. J. Fungi (Basel) 5, 26. doi: 10.3390/jof5010026

Prasad, R., and Rawal, M. K. (2014). Efflux pump proteins in antifungal resistance. Front. Pharmacol. 5, 202. doi: 10.3389/fphar.2014.00202

Rammaert, B., Lanternier, F., Zahar, J.-R., Dannaoui, E., Bougnoux, M.-E., Lecuit, M., et al. (2012). Healthcare-associated mucormycosis. Clin. Infect. Dis. 54 Suppl 1, S44-S54. doi: 10.1093/cid/cir867

Rawal, M., Banerjee, A., Shah, A., Khan, M. F., Sen, S., Saxena, A. K., et al. (2016). Newly identified motifs in Candida albicans Cdrl protein nucleotide binding domains are pleiotropic drug resistance subfamily-specific and functionally asymmetric. Sci. Rep. 6, 27132. doi: 10.1038/srep27132

Reiner, S., Micolod, D., Zellnig, G., and Schneiter, R. (2006). A genomewide screen reveals a role of mitochondria in anaerobic uptake of sterols in yeast. Mol. Biol. Cell 17, 90-103. doi: 10.1091/mbc.e05-06-0515

Rex, J.Clinical (2008). Reference method for broth dilution antifungal susceptibility testing of filamentous fungi : Approved standard. undefined. Available at: paper/Reference-method-for-broth-dilution-antifungal-of- $\%$ 3A-Rex-Clinical/cb65d2f9705fclefdbd0ed2f9b3bf1cccd6836b5 (Accessed January 6, 2021).

Riley, T. T., Muzny, C. A., Swiatlo, E., and Legendre, D. P. (2016). Breaking the Mold: A Review of Mucormycosis and Current Pharmacological Treatment Options. Ann. Pharmacother. 50, 747-757. doi: 10.1177/1060028016655425

Rocha, M. F. G., Bandeira, S. P., de Alencar, L. P., Melo, L. M., Sales, J. A., Paiva, M. de A.N., et al. (2017). Azole resistance in Candida albicans from animals: Highlights on efflux pump activity and gene overexpression. Mycoses 60, 462468. doi: $10.1111 /$ myc. 12611

Roden, M. M., Zaoutis, T. E., Buchanan, W. L., Knudsen, T. A., Sarkisova, T. A., Schaufele, R. L., et al. (2005). Epidemiology and outcome of zygomycosis: a review of 929 reported cases. Clin. Infect. Dis. 41, 634-653. doi: 10.1086/432579

Roilides, E., Kontoyiannis, D. P., and Walsh, T. J. (2012). Host defenses against zygomycetes. Clin. Infect. Dis. 54, S61-S66. doi: 10.1093/cid/cir869

Ruiz-Vázquez, R. M., Nicolás, F. E., Torres-Martínez, S., and Garre, V. (2015). Distinct RNAi Pathways in the Regulation of Physiology and Development in the Fungus Mucor circinelloides. Adv. Genet. 91, 55-102. doi: 10.1016/ bs.adgen.2015.07.002

Sambrook, J., Fritsch, E. F., and Maniatis, T. (1989). Molecular cloning: a laboratory manual (Cold Spring Harbor, N.Y: Cold Spring Harbor Laboratory).

Sanglard, D., and Coste, A. T. (2015). Activity of Isavuconazole and Other Azoles against Candida Clinical Isolates and Yeast Model Systems with Known Azole Resistance Mechanisms. Antimicrob. Agents Chemother. 60, 229-238. doi: 10.1128/AAC.02157-15

Sanglard, D., Ischer, F., and Bille, J. (2001). Role of ATP-Binding-Cassette Transporter Genes in High-Frequency Acquisition of Resistance to Azole Antifungals in Candida glabrata. Antimicrob. Agents Chemother. 45, 11741183. doi: 10.1128/AAC.45.4.1174-1183.2001

Sanguinetti, M., Posteraro, B., La Sorda, M., Torelli, R., Fiori, B., Santangelo, R., et al. (2006). Role of AFR1, an ABC Transporter-Encoding Gene, in the In Vivo Response to Fluconazole and Virulence of Cryptococcus neoformans. Infect. Immun. 74, 1352-1359. doi: 10.1128/IAI.74.2.1352-1359.2006

Seeger, M. A., and van Veen, H. W. (2009). Molecular basis of multidrug transport by ABC transporters. Biochim. Biophys. Acta 1794, 725-737. doi: 10.1016/ j.bbapap.2008.12.004

Sharma, C., and Chowdhary, A. (2017). Molecular bases of antifungal resistance in filamentous fungi. Int. J. Antimicrob. Agents 50, 607-616. doi: 10.1016/ j.ijantimicag.2017.06.018

Sionov, E., Chang, Y. C., Garraffo, H. M., Dolan, M. A., Ghannoum, M. A., and Kwon-Chung, K. J. (2012). Identification of a Cryptococcus neoformans cytochrome P450 lanosterol 14 $\alpha$-demethylase (Erg11) residue critical for differential susceptibility between fluconazole/voriconazole and itraconazole/ posaconazole. Antimicrob. Agents Chemother. 56, 1162-1169. doi: 10.1128/ AAC.05502-11
Skiada, A., Lass-Floerl, C., Klimko, N., Ibrahim, A., Roilides, E., and Petrikkos, G. (2018). Challenges in the diagnosis and treatment of mucormycosis. Med. Mycol. 56, S93-S101. doi: 10.1093/mmy/myx101

Smriti, null., Krishnamurthy, S., Dixit, B. L., Gupta, C. M., Milewski, S., and Prasad, R. (2002). ABC transporters Cdrlp, Cdr2p and Cdr3p of a human pathogen Candida albicans are general phospholipid translocators. Yeast 19 , 303-318. doi: 10.1002/yea.818

Steinegger, M., and Soding, J. (2017). MMseqs2 enables sensitive protein sequence searching for the analysis of massive data sets. Nat. Biotechnol. 35, 1026-1028. doi: $10.1038 /$ nbt. 3988

Sun, H.-Y., and Singh, N. (2011). Mucormycosis: its contemporary face and management strategies. Lancet Infect. Dis. 11, 301-311. doi: 10.1016/S14733099(10)70316-9

Tsao, S., Rahkhoodaee, F., and Raymond, M. (2009). Relative contributions of the Candida albicans $\mathrm{ABC}$ transporters $\mathrm{Cdr} 1 \mathrm{p}$ and $\mathrm{Cdr} 2 \mathrm{p}$ to clinical azole resistance. Antimicrob. Agents Chemother. 53, 1344-1352. doi: 10.1128/ AAC.00926-08

van Heeswijck, R., and Roncero, M. I. G. (1984). High frequency transformation of Mucor with recombinant plasmid DNA. Carlsberg Res. Commun. 49, 691. doi: 10.1007/BF02907500

Vellanki, S., Navarro-Mendoza, M. I., Garcia, A. E., Murcia, L., Perez-Arques, C., Garre, V., et al. (2018). Mucor circinelloides: Growth, Maintenance and Genetic Manipulation. Curr. Protoc. Microbiol. 49, e53. doi: 10.1002/cpmc.53

Vellanki, S., Billmyre, R. B., Lorenzen, A., Campbell, M., Turner, B., Huh, E. Y., et al. (2020). A novel resistance pathway for calcineurin inhibitors in the human-pathogenic Mucorales Mucor circinelloides. mBio 11, e02949-e02919. doi: $10.1128 / \mathrm{mBio} .02949-19$

Walther, G., Wagner, L., and Kurzai, O. (2019). Updates on the Taxonomy of Mucorales with an Emphasis on Clinically Important Taxa. J. Fungi (Basel) 5, 106. doi: $10.3390 /$ jof5040106

White, T. C., Marr, K. A., and Bowden, R. A. (1998). Clinical, cellular, and molecular factors that contribute to antifungal drug resistance. Clin. Microbiol. Rev. 11, 382-402. doi: 10.1128/CMR.11.2.382

Wilcox, L. J., Balderes, D. A., Wharton, B., Tinkelenberg, A. H., Rao, G., and Sturley, S. L. (2002). Transcriptional profiling identifies two members of the ATP-binding cassette transporter superfamily required for sterol uptake in yeast. J. Biol. Chem. 277, 32466-32472. doi: 10.1074/jbc.M204707200

Wilkens, S. (2015). Structure and mechanism of ABC transporters. F1000Prime Rep. 7, 14. doi: 10.12703/P7-14

$\mathrm{Yu}, \mathrm{Z}$., and Fischer, R. (2019). Light sensing and responses in fungi. Nat. Rev. Microbiol. 17, 25-36. doi: 10.1038/s41579-018-0109-x

Zavrel, M., Hoot, S. J., and White, T. C. (2013). Comparison of sterol import under aerobic and anaerobic conditions in three fungal species, Candida albicans, Candida glabrata, and Saccharomyces cerevisiae. Eukaryot Cell 12, 725-738. doi: 10.1128/EC.00345-12

Zhang, Y., Navarro, E., Cánovas-Márquez, J. T., Almagro, L., Chen, H., Chen, Y. Q., et al. (2016). A new regulatory mechanism controlling carotenogenesis in the fungus Mucor circinelloides as a target to generate $\beta$-carotene overproducing strains by genetic engineering. Microb. Cell Fact 15, 99. doi: 10. 1186/s12934-016-0493-8

Conflict of Interest: The authors declare that the research was conducted in the absence of any commercial or financial relationships that could be construed as a potential conflict of interest.

Copyright (c) 2021 Nagy, Kiss, Varghese, Bauer, Szebenyi, Kocsubé, Homa, Bodai, Zsindely, Nagy, Vágvölgyi and Papp. This is an open-access article distributed under the terms of the Creative Commons Attribution License (CC BY). The use, distribution or reproduction in other forums is permitted, provided the original author $(s)$ and the copyright owner(s) are credited and that the original publication in this journal is cited, in accordance with accepted academic practice. No use, distribution or reproduction is permitted which does not comply with these terms. 